\title{
Concrete creep at variable humidity: constitutive law and mechanism
}

\author{
Z. P. Bažant
}

Active Member, RILEM. Professor of Civil Engineering and Director, Center for Concrete and Geomaterials, Technological Institute, Northwestern University, Evanston, Illinois 60201, U.S.A.

\section{J. C. Chern}

Graduate Research Assistant, Northwestern University, presently Research Engineer, Division of Reactor Analysis and Safety, Argonne National Laboratory, Argonne, Illinois 60439, U.S.A.

\begin{abstract}
The previously formulated rate-type aging creep law based on Maxwell chain is generalized to variable humidity and is calibrated by extensive comparisons with test data from the literature. The main object of attention is the Pickett effect, i.e., the apparent increase in creep due to drying simultaneous with loading. This effect is shown to have four sources, in their decreasing order of importance: (1) stress-induced shrinkage, (2) tensile strain softening due to progressive cracking, (3) irreversibility of unloading contraction after tensile strainsoftening, and (4) increase of material stiffness due to aging (hydration). The model, which is a special case of a previously advanced thermodynamic theory, depends on only one hypothesis about the microscopic physical mechanism of creep: The creep rate depends on the magnitude of the flux of microdiffusion of water between the macropores (capillary pores) and the micropores in the cement gel. By assuming this microdiffusion to be infinitely fast, the effect is reduced to a dependence of creep viscosities on the time rate of pore humidity, and this is further shown to be equivalent to stress-induced shrinkage, in which the shrinkage coefficient defining the ratio of the increments of shrinkage strain and pore relative humidity depends on stress. In three dimensions, the shrinkage coefficient thus becomes a tensor. For thermodynamic reasons, there must also exist stress-induced thermal expansion. Although tensile cracking is found to make significant contribution to the Pickett effect, it is far from sufficient to explain it fully. The theory agrees with test data on basic creep, creep of specimens with reduced water content at hygral equilibrium (predried), shrinkage, swelling, and creep at drying under compression, tension, or bending. The strainsoftening model used for tensile cracking is the same as that used previously to fit test data from fracture tests, direct tensile tests, and deflection tests of reinforced beams.
\end{abstract}

\section{INTRODUCTION}

At simultaneous drying, the deformation of a concrete specimen under sustained load is larger than the sum of the drying shrinkage deformation of the specimen at no load and of the deformation of the specimen which does not dry, i. e., is sealed ( fig. $1 \mathrm{~b}$ ). The excess deformation may be regarded either as drying-induced creep (in short the drying creep) or as load-induced shrinkage. This phenomenon, called the Pickett effect [47] after the man who first clearly documented it and subjected it to detailed analysis, has a complex physical mechanism, the true nature of which is only now emerging. The purpose of the present study is to present a mathematical model which describes the Pickett effect and agrees with all important experimental data on creep and shrinkage.

\section{PREVIOUS WORKS AND NATURE OF PROBLEM}

Based on his bending creep tests, Pickett [47] assumed the excess deformation to be caused by a nonlinearity in the relation between creep strain and stress. This explanation is still in essence valid, although it misses the tensile strain-softening due to microcracking, the most important aspect of the nonlinearity which was not known in Pickett's time, and ignores other physical phenomena which make equally significant contributions.

When drying creep was observed under compression, tension and torsion, it became clear that one must search for further explanations. Various physical mechanisms were proposed but later disproved. One was the seepage theory which assumed that creep may be caused by consolidation like that in clays, during which 
the pore water is squeezed out of the specimen under load ([48], [53]). This idea, however, contradicts the fact that compressive stress causes no increase in water loss of concrete, and that creep of sealed concrete is not negligible. Moreover, it is hard to explain how an appreciable part of the applied stress should be transferred to water, given that its volume compressibility is about 20-times larger than that of concrete.

Another suggestion, known as the viscous shear theory [1], was that creep is caused by sliding of cement gel particles and that the macroscopic flux of water through concrete increases the sliding rate due to creating disorder in the cement paste microstructure. This idea was later disproved by tests of specimens through which water permeated at a constant rate so that pore water content was constant in time at each point of the specimen while being distributed nonuniformly across the specimen thickness. No increase of creep was observed under these conditions.

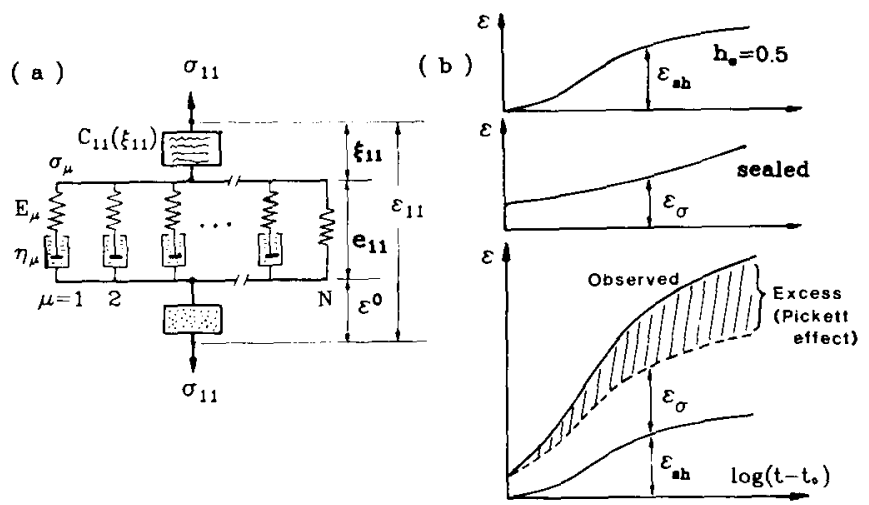

Fig. 1. - Sketch of Pickett effect.

Using the rate-process theory with activation energy, Wittmann ([40], [54], [57], [59]) theorized that the surface tension produced by drying in the pores of cement paste subjected the solid microstructure to an increased compression, thus producing higher creep per unit stress due to nonlinear dependence of the creep rate on stress, as described by the hyperbolic sine law. Although Wittmann's recourse to the rate-process theory is in principle correct, it alone, however, seems to fail when one considers drying creep in shear, tension, and partly also bending, or a similar deformation increase observed at wetting simultaneous with creep, or in creep recovery simultaneous with a change in humidity.

One difficulty with the theories involving water movement caused by load has been the fact that, especially in partially dried concrete, the capillary pore water cannot transmit an appreciable part of the applied load. This difficulty was circumvented by Powers [48] in his thermodynamic theory (preceded by a similar nonthermodynamic explanation by Hrennik of [35]). Powers pointed out that water molecules in hindered absorbed layers within gel pores of molecular dimensions can transmit enormous pressures in an equilibrium state and at the same time be mobile, i. e. exit the pores as a result of drying. Creep would then be caused by diffusion of water molecules out of (or into) the hindered absorbed layers. This explanation allowed for the fact that the lower the moisture content, the lower the steady-state creep rate, as discovered during the 1960's ([26], [32], [52], [46], [53], [58]). The concept of loadbearing adsorbed water could not, however, explain why there should be excess deformation during simultaneous drying, and also it could not be reconciled with several quantitative characteristics of creep (see pp. 4547 of reference [5]).

Powers' thermodynamic analysis was refined in references [5], [6], [9], [19], which introduced surface thermodynamics and treated the cement paste as a two-phase material with diffusion of both pore water and solid particles, only the latter one being considered as the direct source of creep. With regard to the Pickett effect, the principal idea was to distinguish the local water diffusion (microdiffusion) between adjacent macropores and micropores from the macroscopic water diffusion and consider that only the microdiffusion makes the solid phase more mobile, thereby increasing creep. This idea worked well in comparison with test data ([33], [41], [55], [5]) and will be also used here.

In reference [19] is was found that an important contribution to the excess deformation at drying is due to tensile nonlinearity, especially the reduction of stress to zero due to cracking. Thus, a significant contribution appeared to arise from the self-equilibrating residual stresses arising from the solution to the field problem with its boundary conditions, rather than from the constitutive equation as such. A similar conclusion was reached by Becker and Bresler [22] in their analysis of shrinkage in columns, and Iding and Bresler [36] in their analysis of test cylinders. Wittmann with Roelfstra [60] examined this phenomenon deeper and called it the apparent mechanism, contrasting it with the real creep mechanism as a point property which belongs into the constitutive equation. In their finite element calculations, the contribution of tensile cracking appeared particularly large and led them to suggest that it might perhaps be the cause of all of the excess deformation at drying. They emphasized that the overall shrinkage of load-free drying specimens can be much less than it would be if these specimens did not undergo cracking or microcracking, and that it is the latter shrinkage which takes place in compressed specimens in which the cracking is prevented. It now appears, however, that although this phenomenon is significant it cannot explain all the excess deformation, not even its major part.

\section{BASIC CONSTITUTIVE PROPERTIES}

\section{Viscoelasticity with aging}

Except for tensile strain-softening which will be treated later, the creep of concrete within the service stress range can be approximately assumed as linearly viscoelastic, however, with a strong aging effect. The 
stress-strain relation is then given by a history integral based on the superposition principle, and the material properties are then fully characterized by the compliance function $J\left(t, t^{\prime}\right)$ (also called the creep function), which represents the strain at age $t$ caused by a unit uniaxial stress acting since age $t^{\prime}$. For numerical computations it is advantageous to convert the integral-type stress-strain relation to a rate-type form, expressed as a system of linear ordinary first-order differential equations. This rate-type form can approximate the most general aging viscoelastic behavior with any desired accuracy. The most effective form of the rate-type creep law is the one visualized by the Maxwell chain model ( fig. 1 a):

$$
\begin{aligned}
& \boldsymbol{\sigma}=\sum_{\mu=1}^{N} \boldsymbol{\sigma}_{\mu}, \\
& \dot{\mathbf{e}}=\frac{1}{E_{\mu}(t)} \mathbf{B} \dot{\boldsymbol{\sigma}}_{\mu}+\frac{1}{\eta_{\mu}(t)} \mathbf{B}^{\prime} \boldsymbol{\sigma}_{\mu},
\end{aligned}
$$

Superior dots denote derivatives with respect to time $t$, $E_{\mu}$ and $\sigma_{\mu}$ are age-dependent uniaxial spring moduli and dashpot viscosities associated with the individual units of the Maxwell chain labeled by subscript $\mu=1, \ldots, N ; \sigma=\left(\sigma_{11}, \sigma_{22}, \sigma_{33}, \sigma_{12}, \sigma_{23}, \sigma_{31}\right)^{T}=\mathrm{co}-$ lumn matrix of stress components ( $T$ denotes the transpose of a matrix), $\sigma_{\mu}$ is an analogous column matrix of the stresses in the individual Maxwell chain units, called the partial stresses or the hidden stresses (internal variables, in the thermodynamic sense), $e$ is an analogous column matrix of strain components representing elastic deformation plus creep without shrinkage; and $\mathbf{B}, \mathbf{B}^{\prime}$ are constant symmetric $6 \times 6$ square matrices, which may be defined in terms of the Poisson ratio $v$ as the material is assumed isotropic (see reference [10]). Normally $\mathbf{B}=\mathbf{B}^{\prime}$ because the Poisson ratios for elastic deformation and for creep are approximately equal. The nonzero components of $\mathbf{B}$ are $B_{11}=B_{22}=B_{33}=1, \quad B_{12}=B_{23}=B_{13}=-v, \quad$ and $B_{44}=B_{55}=B_{66}=2(1+v)$ if matrix e involves the shear angles $\gamma$ rather than the tensorial shear strains $\gamma / 2$.

An efficient computer subroutine for determining $E_{\mu}(t)$ and $\eta_{\mu}(t)$ from any given compliance function $J\left(t, t^{\prime}\right)$ is available [4] and has been used in the present calculations. At reference temperatures the viscosities are given as $\eta_{\mu}(t)=\tau_{\mu} E_{\mu}(t)$ where $\tau_{\mu}$ are the relaxation times, which may be considered to be spaced by decades in the log-time scale. The compliance function from which the computer evaluates $E_{\mu}(t)$ and $\eta_{\mu}(t)$ has been assumed in the present calculation in the form of the double power law ([14], [15], [16]) although for greater accuracy the new log-double power law could be used [11]. Note that no terms due to drying, such as those used in the BP-model ([15], [16]), should be included in the compliance function because drying is taken into account separately.

\section{Humidity effect}

The rate of hydration strongly depends on the relative humidity $h$ in the pores of concrete. At low $h$, the hydration rate is virtually zero, and then there is no aging. This is usually described by means of a change of time scale, considering that the age-dependent material parameters, i. e., $E_{\mu}$ and $\eta_{\mu}$, rather than being functions of the actual age of concrete $t$, are functions of the socalled equivalent hydration period $t_{e}([7],[8],[12])$.

$t_{e}=\int \beta_{h} \mathrm{~d} t, \quad E_{\mu}=E_{\mu}\left(t_{e}\right), \quad \eta_{\mu}=\eta_{\mu}\left(t_{e}\right)$,

in which $\beta_{h}$ is an empirical function of pore humidity $h$, and may be considered as $\beta_{h}=\left[1+(a-a h)^{4}\right]^{-1}$. According to test data [50], [59], [44], $a \simeq 5$.

The lower the pore humidity, the smaller is the creep rate, provided that the specimen is in hygral equilibrium. This fact, at first perplexing, was established during the 1960's ([53], [58]) by measurements on very thin specimens which had been brought to hygral equilibrium at some constant reduced humidity prior to applying the sustained load. This phenomenon, which invalidated previous explanations of the excess creep at drying as a consequence of decreased viscosity, may be described in the context of the Maxwell chain model as:

$\frac{1}{\eta_{\mu}(t)}=\frac{\varphi_{h}}{\tau_{\mu} E_{\mu}(t)}$,
$\varphi_{h}=\alpha_{h}+\left(1-\alpha_{h}\right) h^{2}$,

in which $\varphi_{h}$ is an empirical function of pore humidity $h$. According to some data for cement paste specimens predried in oven and then rewetted [59], constant $\alpha_{h}$ may be as small as 0.1 , however, a larger value, $\alpha_{h} \simeq 0.5$ [9], has been found to work well for most concretes and has been used in the present computations.

\section{Nonlinearity}

Although we do not aim to study nonlinear triaxial creep, we need at least an approximate characterization of the nonlinear dependence of compression creep on stress for moderately high compressive stresses (up to about $75 \%$ of the uniaxial strength). For the present computations, this has been expediently achieved by replacing the column matrix of linear viscoelastic strains $\left(e_{11}, e_{22}, e_{33}, e_{12}, e_{23}, e_{31}\right)$ (see reference [16]) with the column matrix $\left(e_{11} f_{1}, e_{22} f_{2}, e_{33} f_{3}, e_{12}, e_{23}\right.$, $\left.e_{31}\right)^{T}$ in which $f_{1}, f_{2}$, and $f_{3}$ are functions of the normal stress components. The nonlinearity in shear is disregarded, but this is of no effect when $e_{11}, e_{22}$, and $e_{33}$ are the principal strains, as is the case here. The functions of stress were considered (similarly to reference [16]) for $\sigma_{11} \geqq 0.4 f_{c}$ as:

$f_{1}=\frac{R\left(\sigma_{11}\right)}{R\left(0.4 f_{c}\right)}$

with:

$R\left(\sigma_{11}\right)=1+4.4\left\{1-\left[1-\left(\frac{\sigma_{11}}{f_{c}}\right)^{5}\right]^{1 / 2}\right\}$ 
in which:

$f_{c}=f_{c}^{\prime}(t)\left\{1-0.111\left[\log \left(t-t^{\prime}\right)\right]^{0.432}\right\}$.

Here $f_{c}^{\prime}$ is the uniaxial compressive strength at age $t^{\prime}$, $f_{c}$ is the strength modified for the duration of loading (this simple expression, of course, does not introduce the effect of stress history); and the expressions for $f_{2}$ and $f_{3}$ are obtained by permutation of subscripts. For most of the calculations, however, the principal compressive stresses were less than $40 \%$ of the strength, and then the stress-strain relation was considered linear, with $f_{1}=f_{2}=f_{3}=1$. For tension, we assume that all nonlinearity is due to tensile strain-softening and that the linearly viscoelastic part of strain needs no adjustment.

\section{Shrinkage}

We need to characterize the free, unrestrained shrinkage at a point of the material, rather than the overall shrinkage of the specimen. Such shrinkage can hardly be directly measured, but must be inferred indirectly from the observed specimen shrinkage. We intend to characterize only the drying shrinkage, caused by a change in specific moisture content or pore relative humidity, and we omit the small autogenous shrinkage and carbonation shrinkage which are not associated with water diffusion.

As proposed by Carlson [25] and Pickett [47], the free shrinkage $\varepsilon_{s}$ is properly considered as a function of the specific water content of concrete, $w$, which in turn is a function of pore relative humidity $h$. Although the dependence of $\varepsilon_{\mathrm{s}}$ on $w$ is very simple (it is approximately linear), it seems more convenient to consider $\varepsilon_{s}$ as a function of $h$ because hydration changes $h$ only by a few percent while it changes the evaporable water content greatly. Therefore, $\varepsilon_{s}=\varepsilon_{s}^{0} f_{s}(h)$ in which $\varepsilon_{s}^{0}$ is the maximum shrinkage, obtained for $h=0$. The function $f_{\mathrm{s}}(h)=1-h^{3}$ is found to give good fits of test data.

There is also some effect of age on the shrinkage strains. Aging, due to hydration, leads to an increase in the stiffness of the solid microstructure, and if the cause of shrinkage is primarily the reaction in solid microstructure that balances the surface tension and tension in the fluid phase, then the shrinkage strain should be inversely proportional to the stiffness of the solid microstructure, and so it should follow the age dependence of the elastic modulus, $E\left(t_{e}\right)$. Therefore, we may set $\varepsilon_{s} \simeq \varepsilon_{s}^{0} g_{s}\left(t_{e}\right) f_{s}(h)$ in which $g_{s}\left(t_{e}\right)$ $=E\left(t_{0}\right) / E\left(t_{e}\right), t_{0}$ is the age at the start of drying, and $E$ is the Young's modulus of concrete. This expression is correct when $h$ varies at constant age, $t_{e}$. When aging occurs at constant $h$, there exists no drying shrinkage, and, therefore, shrinkage increments during time $\mathrm{d} t$ should be calculated as:

$$
\begin{aligned}
& \mathrm{d} \varepsilon_{s}=\kappa \mathrm{d} h \quad \text { with } \quad \kappa=\varepsilon_{s}^{0} \psi, \\
& \psi=g_{s}\left(t_{e}\right) \frac{\mathrm{d} f_{s}(h)}{\mathrm{d} h} .
\end{aligned}
$$

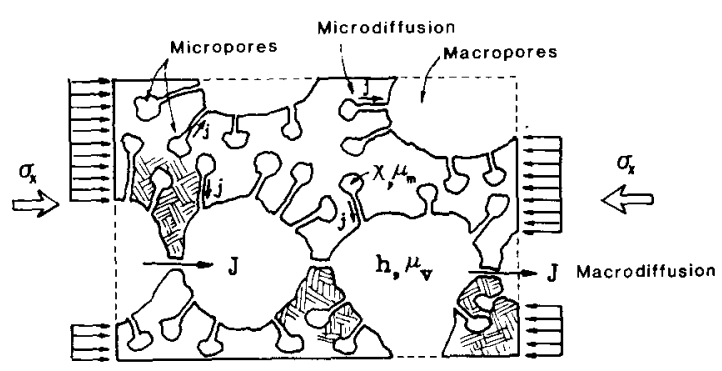

Fig. 2. - Diffusion process in cement paste under applied stresses.

\section{STRESS-INDUCED SHRINKAGE}

Extensive analyses of test data using the foregoing constitutive properties enhanced with the model for tensile cracking and strain-softening from reference [10] have shown that a satisfactory agreement cannot be achieved. It has been found, however, that it can be achieved if the shrinkage coefficient $\kappa$ is considered to be a function of stress. Can a dependence of $\kappa$ on stress be justified physically?

It is now interesting to observe that one very different material - wood- has creep properties similar to concrete, including the drying creep effect [2]. This is quite striking, given that the microstructures and especially the chemical natures of these two materials are entirely different. It follows that the Pickett effect must be caused by some elementary microstructural properties common to both materials. These properties appear to be: (1) the fact that both materials are strongly hydrophyllic, and (2) the fact that they involve two systems of pores: the micropores, which have molecular dimensions, and the macropores, which have much larger, capillary dimensions. For concrete, the micropores are represented by the gel pores in the hardened portland cement paste.

In accordance with this pore subdivision, two different types of water diffusion need to be distinguished: (1) the macrodiffusion, which effects the macroscopic water transport, i. e., the drying or wetting, and (2) the microdiffusion, which transports water into or out the micropores ( fig. 2). The microdiffusion must predominately happen as water transport between a macropore and an adjacent micropore. The vectors of displacements due to microdiffusion have all directions with equal probability, and so these vectors must have a zero resultant. Thus, no net macroscopic movement of water results from the microdiffusion; it results exclusively from the macrodiffusion.

Within each macropore, thermodynamic equilibrium between the various phases of water (vapor, liquid capillary water and adsorbed water) may be assumed to get established immediately and exist all the time. On the other hand, thermodynamic equilibrium between water in the macropore and the adjacent micropores gets established with some delay, albeit possibly very short, and the thermodynamic imbalance is the driving force of the microdiffusion. 
The details of the creep mechanism in concrete are still being disputed; however, most experts would agree that the ultimate physical source of creep is some kind of debonding and rebonding of solid particles or molecules forming the calcium silicate structure of cement gel. Whether this debonding and rebonding also involves large displacements of some solid particles (diffusion), is for us unimportant. Only two aspects are important for explaining the Pickett effect, and they may be briefly summarized by the following two hypotheses (which may be common to concrete and wood):

\section{Hypothesis I}

Unlike the macrodiffusion, the microdiffusion of water disrupts the solid microstructure of cement gel by promoting the debonding and rebonding process that is the source creep.

\section{Hypothesis II}

The microdiffusion may be considered as infinitely fast, i. e., its half-time infinitely short.

One might add the hypothesis that the macrodiffusion passages of water bypass most of the micropores. However, this is more a necessity than a hypothesis; it must be true or else the steady-state permeation of water through a concrete specimen should alter its creep, which it does not. Because, for concretes of a low water-cement ratio, the capillaries are known to be discontinuous, the macrodiffusion passages must traverse some part of the micropore volume, but this part must be only a small fraction of the total micropore volume (this is supported by a previous [3] explanation of a 200 -fold increase of permeability upon heating over $100^{\circ} \mathrm{C}$ ).

With regard to hypothesis II, let us estimate the microdiffusion rate. The spacing of the capillary pores (macropores) is of the order of $10^{-5} \mathrm{~m}$. At the same diffusivity, the diffusion half-times are proportional to the square of the distance. For a normal low-porosity concrete, the diffusion half-time for a wall $0.15 \mathrm{~m}$ thick is about 1 year. Thus, for the microdiffusion, the halftime would be about

$1 \times 365 \times 3600 \times 24 \times\left(10^{-5}\right)^{2} / 0.15^{2}=1.4$ second.

Since the microdiffusion passes through smaller pores than the macrodiffusion, the actual half-time is likely to be longer, but not many orders of magnitude longer.

Let us formulate these ideas mathematically. Water diffusion between the macropore and the adjacent micropores must be driven by a difference between the chemical potential $\mu_{v}$ (Gibbs free energy per unit mass) of water vapor in the macropore and the chemical potential $\mu_{m}$ of water in the adjacent micropores. $\mu_{v}$ is a function of the relative vapor pressure $h$ in the pore (pore humidity) and temperature $T$, and so $h=f_{1}\left(\mu_{v}\right.$, $T$ ), where $f_{1}$ is a certain function. At thermodynamic equilibrium, the chemical potential of water, $\mu_{m}$, in the micropores must be equal to $\mu_{v}$. The state of water in the micropores may be conveniently characterized by relative humidity $\chi$ for which the macropore water is in thermodynamic equilibrium. Then the flux $j$ of water (per unit volume of concrete) from the macropores into the adjacent micropores ( fig. 2) at uniform temperature may be expressed as:

$j=b_{1}(h-\chi)$,

in which $b_{1}$ is a local permeability coefficient. Flux $j$ is a scalar since the microdiffusion involves all possible directions. The chemical potential of micropore water is a function of its spreading pressure $\pi_{m}$ and temperature $T$, and $\pi_{m}$ is further a function of $T$ and the specific mass $w_{m}$ of water in the micropores. Then, noting that $\chi=f_{1}\left(\mu_{m}, T\right)$, we see that $w_{m}=w_{m}\left(\chi_{1}, T\right)$. Conservation of mass requires that:

$j=\dot{w}_{m}=\left(\partial w_{m} / \partial \chi\right) \dot{\chi}+\left(\partial w_{m} / \partial T\right) \dot{T}$.

Combining this with equation (6) we obtain the following governing equation for the microdiffusion process:

$\dot{\chi}=b_{m}(h-\chi)-c_{m} \dot{T}$,

in which:

$b_{m}=\frac{b_{1}}{\left(\partial w_{m} / \partial \chi\right)_{T}}, \quad c_{m}=\frac{\left(\partial w_{m} / \partial T\right)_{\chi}}{\left(\partial w_{m} / \partial \chi\right)_{T}}$

Consider now the solution of this equation. In a sufficiently short time interval $\Delta t, h$ may be assumed to vary linearly with time, i. e., $h=h_{1}+\dot{h}_{0} t$ in which $h_{1}$ and $\dot{h}_{0}$ are constants. Coefficients $b_{m}$ and $c_{m}$ may be also considered constant during a short interval $\Delta t$. The solution of equation (7) then has the form $\chi=\chi_{1}+\dot{\chi}_{0} t+C_{1} \exp \left(-b_{m} t\right)$ in which $\chi_{1}, \dot{\chi}_{0}$ and $C_{1}$ are constants. According to hypothesis II, $b_{m}$ must be very large and so the exponential term is negligible. Hence, $\chi=\chi_{1}+\dot{\chi}_{0} t$, and substituting this along with $h=h_{1}+\dot{h}_{0} t$ into equation (7), we obtain:

$\left[b_{m}\left(h_{1}-\chi_{1}\right)-c_{m} \dot{T}-\dot{\chi}_{0}\right]+\left[b_{m}\left(\dot{h}_{0}-\dot{\chi}_{0}\right)\right] t=0$.

Since this must hold for all $t$, each bracketed term must vanish separately, which yields $\dot{\chi}_{0}=\dot{h}_{0}$, $h_{1}-\chi_{1}=\left(\dot{\chi}_{0}+c_{m} \dot{T}\right) / b_{m}, \quad$ and consequently $h-\chi=\left(\dot{h_{0}}+c_{m} \dot{T}\right) / b_{m}$ where we may write $\dot{h}$ instead of $\dot{h}_{0}$. Thus, according to equation (6) we conclude that, as a good approximation:

$j=a_{1} \dot{h}+a_{2} \dot{T}$,

in which $a_{1}$ and $a_{2}$ are certain constants.

In view of hypothesis $I$, the differential equation for a single Maxwell unit with spring modulus $E$, dashpot viscosity $\tilde{\eta}$, and stress $\sigma$ may be written as:

$\frac{\dot{\sigma}}{E}+\frac{\sigma}{\tilde{\eta}(j)}=\dot{\varepsilon}-\kappa_{0} \dot{h}-\alpha_{0} \dot{T}+k_{m} j$,

in which $\varepsilon=$ strain, including shrinkage and thermal expansion; coefficients $\alpha_{0}$ and $\kappa_{0}$ and $k_{m}$ are independent of $j, \dot{h}$ and $T$; terms $\alpha_{0} \dot{T}$ and $\kappa_{0} \dot{h}$ represent the rates of thermal expansion and shrinkage without the effect of microdiffusion $(j=0)$, and term $k_{m} j$ represents the rate of shrinkage caused by the removal of water 
from the micropores. Substituting equation (9) for $j$ we have:

$$
\begin{aligned}
& \frac{\dot{\sigma}}{E}+\frac{\sigma}{\tilde{\eta}(\dot{h}, \dot{T})}=\dot{\varepsilon}-\bar{\kappa} \dot{h}-\bar{\alpha} \dot{T}, \\
& \bar{\kappa}=\kappa_{0}-k_{m} a_{1}, \quad \bar{\alpha}=\alpha_{0}-k_{m} a_{2},
\end{aligned}
$$

in which $\bar{\kappa}$ and $\bar{\alpha}$ are independent of $\dot{h}$ and $\dot{T}$, and $\tilde{\eta}$ is a variable viscosity depending on $j$, or $\dot{h}$ and $\dot{T}$.

Another question now arises: Does positive $j$ (entry of water into the micropores) decrease compressive $\dot{\varepsilon}$ (creep rate) and increase tensile $\dot{\varepsilon}$, and does negative $j$ (exit of water from the micropores) increase compressive $\dot{\varepsilon}$ and decrease tensile $\dot{\varepsilon}$, or does $j$ of any sign (i. e., the magnitude of $j$ ) always increase $\dot{\varepsilon}$ ? The former must be true because exit of water molecules promotes ruptures of the compressed bonds (the same as compression creep), while entry of water molecules promotes ruptures of the tensioned bonds (the same as tensile creep). Hence, $1 / \tilde{\eta}$ as a function of $j$ should not have a minimum at $j=0$ but should increase as $j$ becomes negative and decrease as $j$ becomes positive. Thus, the linear terms of Taylor series expansion of $1 / \tilde{\eta}$ as a function of $\dot{h}$ and $\dot{T}$ should be present and should dominate at sufficiently small $\dot{h}$ and $\dot{T}$. Therefore, we may introduce the approximation:

$\frac{1}{\tilde{\eta}}=\frac{1}{\eta}-\kappa^{\prime} \dot{h}-\alpha^{\prime} \dot{T}$

in which $\eta, \kappa^{\prime}$ and $\alpha^{\prime}$ are independent of $j$ or $\dot{h}$ and $\dot{T}$. Substituting equation (12) in equation (11), we get:

$$
\begin{aligned}
& \frac{\dot{\sigma}}{E}+\frac{\sigma}{\eta}=\dot{\varepsilon}-\dot{\varepsilon}_{s}-\dot{\varepsilon}_{T}, \\
& \dot{\varepsilon}_{s}=\kappa \dot{h}, \quad \dot{\varepsilon}_{T}=\alpha \dot{T},
\end{aligned}
$$

in which

$\kappa=\varepsilon_{s}^{0} \psi(1-r \sigma), \quad \alpha=\bar{\alpha}(1-\rho \sigma)$,

with:

$\bar{\kappa}=\varepsilon_{s}^{0} \psi, \quad \kappa^{\prime}=\bar{\kappa} r, \quad \alpha^{\prime}=\bar{\alpha} \rho$,

where $\kappa$ and $\alpha$ are the shrinkage coefficient and the thermal expansion coefficient, and viscosity $\eta$ is independent of $j$ or $\dot{h}$ and $\dot{T}$. Analysis of test data shows that $r$ is usually between $0.1 / f_{t}^{\prime}$ to $0.6 / f_{t}^{\prime}$ and $\rho$ is roughly $2 / f_{t}^{\prime}$, (always $r f_{t}^{\prime}<1$ and $\rho f_{t}^{\prime}<1$ since $\kappa$ and $\alpha$ may not be negative).

In equation (11), the effect of humidity variation is that of modified viscosity, causing drying-induced creep. On the other hand, in equation (13), the drying effect appears only in coefficients $\kappa$ and $\alpha$ which represent the stress-induced shrinkage and the stress-induced thermal expansion. It is now interesting to observe that these two phenomena, the drying-induced creep and the stress-induced shrinkage, are mathematically equivalent.
For further considerations, we use the viewpoint of stress-induced shrinkage, which is simpler when a chain of parallel Maxwell units is considered. In generalizing equation (13) for the Maxwell chain model for uniaxial creep, we assume, for the sake of simplicity, that $\kappa$ and $\alpha$ are functions of the total stress $\sigma$ rather than the partial stress $\sigma_{\mu}$. Then:

$\frac{\dot{\sigma}_{\mu}}{E_{\mu}(t)}+\frac{\sigma_{\mu}}{\eta_{\mu}(t)}=\dot{\varepsilon}-\kappa \dot{h}-\alpha \dot{T}$,

in which $\kappa$ and $\alpha$ are given by equation (14) and $\sum_{\mu} \sigma_{\mu}=0$.

It is now interesting to observe that not only the shrinkage coefficient $\kappa$ but also the thermal expansion coefficient $\alpha$ is stress-dependent. This means that if there is stress-induced shrinkage, there should also be stress-induced thermal dilatation. This conclusion is a consequence of the fact that the chemical potential of water is a function of not only its pressure but also temperature, and that the sorption relation between the water content and the pressure also involves temperature. (The existence of stress-induced thermal expansion was implied in Bažant's 1969 thermodynamic model [6, 7, 8]: see discussion of equation 21 below.)

How should the stress-induced shrinkage and thermal expansion, given by the stress-induced terms in equation (14), be generalized to three dimensions? Restricting attention to the simplest, linear dependence on stress, the shrinkage coefficients and the thermal expansion coefficients for the three principal stress directions may be most generally expressed as:

$\kappa_{1}=\varepsilon_{s}^{0} \psi\left(1-r \sigma_{1}-r^{\prime} \sigma_{0}\right)$,

$\kappa_{2}=\varepsilon_{s}^{0} \psi\left(1-r \sigma_{2}-r^{\prime} \sigma_{0}\right)$,

$\kappa_{3}=\varepsilon_{s}^{0} \psi\left(1-r \sigma_{3}-r^{\prime} \sigma_{0}\right)$.

$\alpha_{1}=\bar{\alpha}\left(1-\rho \sigma_{1}-\rho^{\prime} \sigma_{0}\right)$,

$\alpha_{2}=\bar{\alpha}\left(1-\rho \sigma_{2}-\rho^{\prime} \sigma_{0}\right)$,

$\alpha_{3}=\bar{\alpha}\left(1-\rho \sigma_{3}-\rho^{\prime} \sigma_{0}\right)$,

in which $\sigma_{1}, \sigma_{2}$, and $\sigma_{3}$ are the principal stresses, $\sigma_{0}=\left(\sigma_{1}+\sigma_{2}+\sigma_{3}\right) / 3=$ mean stress, and $r_{1}, r^{\prime}, \rho$ and $\rho^{\prime}$ are coefficients which in general depend on pore humidity and temperature but not on their rates. Heeding the conditions of isotropy, the stress-strain relation corresponding to Maxwell chain (equation (1)) must have in three dimensions the form:

$\sigma=\sum_{\mu} \sigma_{\mu}$

$\left.\frac{1}{E_{\mu}(t)} \mathbf{B} \dot{\boldsymbol{\sigma}}_{\mu}+\frac{1}{\eta_{\mu}(t)} \mathbf{B}^{\prime} \boldsymbol{\sigma}_{\mu}=\dot{\boldsymbol{\varepsilon}}\right) \boldsymbol{x} \dot{\boldsymbol{h}}-\boldsymbol{\alpha} \dot{\boldsymbol{T}}$,

in which $x$ and $\alpha$ represent the column matrices of the components of the shrinkage coefficient tensor and the thermal expansion coefficient tensor. Given that the dependence on the stress tensor $\sigma_{i j}$ is linear and that the isotropy conditions must be satisfied, the most general form of these tensors is: 
$\kappa_{i j}=\varepsilon_{s}^{0} \psi\left(\delta_{i j}-r \sigma_{i j}-r^{\prime} \sigma_{0} \delta_{i j}\right)$

$\left(3 \sigma_{0}=\sigma_{k k}\right)$,

$\alpha_{i j}=\bar{\alpha}\left(\delta_{i j}-\rho \sigma_{i j}-\rho^{\prime} \sigma_{0} \delta_{i j}\right)$,

in which $\delta_{i j}=$ Kronecker delta. It is obvious that for principal stress directions equations (19)-(20) reduce to equation (16)-(17).

In the analysis of test data it appeared that satisfactory fits can be achieved with $r^{\prime}=0$. So the shrinkage coefficient in a certain direction seems to be affected only by the normal stress in that same direction and not by the transverse normal stresses. The same may be suspected to be true for $\rho^{\prime}$.

From a strictly phenomenological viewpoint, we might have introduced equations (19)-(20) directly as the basic hypothesis instead of hypotheses I and II. This would be, however, without any physical justification. We see no way of justifying the dependence of the shrinkage coefficient on the stress except as a consequence of its dependence on the water flux in the microdiffusion.

The deformation response depends on the product of stress and humidity rate (or imbalance of the potential causing microdiffusion). So it depends on the product of the thermodynamic driving forces of viscoelastic deformation and of shrinkage. Thus, the stress-induced shrinkage and thermal dilatation represent what is called in thermodynamics the cross effects.

It is interesting to relate our formulation to a previous thermodynamically based theory from references [5], [6], [8], [19], [39]. In that theory, distinction was made between stress $\sigma_{w}$ transmitted by load-bearing water in the gel pores (hindered absorbed layers and interlayer water) and stress $\sigma_{s}$ transmitted only by solid-to-solid contacts. The differential equation corresponding to one unit of the Maxwell chain (see equations (1), (10)-(13) of reference [19]) was introduced as:

$\dot{\sigma}_{s}+\varphi_{s s}(S) \sigma_{s}+\varphi_{s w} S=E_{s}\left(\dot{e}-\kappa_{0} \dot{h}-\alpha_{0} \dot{T}\right)$,

$\dot{\sigma}_{w}+\varphi_{w s}(S) \sigma_{s}+\varphi_{w w} S=E_{w}\left(\dot{e}-\kappa_{0} \dot{h}-\alpha_{0} \dot{T}\right)$,

in which $E_{w}$ and $E_{s}$ are the spring moduli for $\sigma_{w}$ and $\sigma_{s}$; and $\varphi_{s s}, \varphi_{s w}, \varphi_{w s}$ and $\varphi_{w w}$ are certain rate coefficients among which $\varphi_{s w}$ and $\varphi_{w s}$ represent thermodynamic cross effects; and $S$ is proportional to $\chi-h$ from equation (6), being defined as $S=\sigma_{w}-f(h, T)$ where $f(h, T)$ is proportional to our $\chi$. Therefore, $S=k_{0} j$ where $k_{0}=$ const. Now, as an approximation we may introduce in equation $(21) \sigma_{s}=(1-n) \sigma$, where $n$ is some porosity coefficient. Then, summing both equations (21) and introducing the notations $E_{w}+E_{s}=E, \quad 1 / \tilde{\eta} \quad(j)=\left[\varphi_{s s}(S)+\varphi_{w s}(S)\right] \quad(1-n) / E$, $k_{m}=\left[\varphi_{s w}(S)+\varphi_{w w}(S)\right] k_{0} / E$, we obtain our previous starting relation, equation $(10)$.

Thus we may conclude that the present formulation is mathematically a special case of the previous thermodynamic theory from references [5], [6], [8] and [19]. Significant simplification has been achieved by virtue of hypothesis II, which was not introduced in those previous works in which a finite delay of response between the macropores and micropores was considered. This previous theory was derived from a rather detailed picture of the microstructure of concrete and the physical mechanism causing creep. Much of this picture was unnecessarily hypothetical. It now appears that the present formulation, representing a greatly simplified special case, does not depend on these particular hypothetical features of the microstructure and the creep mechanism which have been questioned. This is a comforting outcome, since the precise nature of the creep mechanism is still being disputed by cement physicists. As we will see, the present simplified theory allows equally good agreement with test data as that demonstrated before ([34], [41], [55]) and also allows fitting new data not available at that time.

\section{COMPUTER PROGRAM}

The constitutive properties of the material are defined by equations (18)-(20) in which $\psi$ is given by equation $(5 b), t_{e}$ and $\varphi_{h}$ are given in equations (2), (3) and $f_{1}$ is given by equation (4). A finite element computer program has been written to analyse, in a step-bystep manner, loaded concrete specimens exposed to a prescribed environment. The program calculates pore humidities in individual finite elements simultaneously with the stress and deformation analysis.

The diffusion of water is calculated in the manner described before [3], [12]. The diffusion equation for pore humidity $h$ is assumed to have a variable diffusivity $C$ which decreases with the equivalent age $t_{e}$ and diminishes by an order of magnitude as $h$ decreases. According to reference [3] or [12] (equation 7.103),

$C=C_{1}\left(t_{e}\right)\left\{\alpha_{0}+\frac{\left(1-\alpha_{0}\right)}{1+(1-h)^{n} /\left(1-h_{c}\right)^{n}}\right\}$

with $\alpha_{0} \simeq 0.05, h_{c} \simeq 0.75$ and $n=6$ to 16 ; and

$C_{1}\left(t_{e}\right)=C_{0}\left(0.3+3.6 t_{e}^{1 / 2}\right)$,

in which $C_{0}$ is the reference diffusivity of given concrete, a constant. The diffusion equation also involves a small correction term for self-desiccation representing the humidity decrease caused by hydration in a sealed element of concrete (see reference [3]).

The computer program also analyzes progressive cracking by means of a strain-softening constitutive relation developed in the preceding work [10]. The total strain including the averaged contribution from microcracking is $\varepsilon=\mathbf{e}+\boldsymbol{\xi}$ in which $\mathbf{e}$ is the strain used in equation (18), representing the elastic deformation plus shrinkage plus creep (and plus thermal expansion), and $\xi$ is the additional strain associated with strainsoftening (smeared-out cracking) as expressed in the previous work (equations (1), (7), (12) in reference [10]). The new exponential algorithm for strain-softening, developed in that work, is used. Unloading and 
reloading after tensile strain-softening is formulated also in the manner developed in this previous work [10].

Two special forms of the finite element program have been developed for the analysis of typical test specimens. One is an axisymmetric one-dimensional finite element program for an infinitely long solid or hollow cylinder, either sealed or exposed to an environment of a given history of relative humidity. The radius of the cylinder is subdivided by $(n-1)$ twonode finite elements, and the unknowns are the radial displacements $u_{k}(k=1, \ldots, m)$ and the axial strain $\varepsilon_{z}$, which is the same for all finite elements. Linear distribution functions are assumed within the finite elements, and one integration point is used for each finite element. Due to the relatively large size of the aggregate, it does not make sense to use very small finite elements; typically, only six finite elements along the radius have been used in analyzing the test data. The matrix equations for the axisymmetric analysis in one dimension are listed in references [7] and [18].

Some of the available test data pertain to prisms. For the sake of simplicity, these were analyzed with the same program replacing the prism by a cylinder of the same volume-to-surface ratio.

Another special form of the finite element program has been written for bending. In this case, the transverse stresses were considered as zero and the transverse displacements were ignored. A rectangular cross section was subdivided by a square grid into square finite elements, $k=1, \ldots, m$. The numerical algorithm leads in each time step to an incremental pseudo-elastic stress-strain relation of the form $\Delta \sigma_{k}=$ $E_{k}^{\prime \prime}\left(\Delta \varepsilon_{k}-\Delta \varepsilon_{k}^{\prime \prime}\right)$, in which $\Delta \sigma_{k}$ and $\Delta \varepsilon_{k}$ are the uniaxial stress and strain increments in the centroid of the finite element, and $\Delta \varepsilon_{k}^{\prime \prime}$ is the increment of inelastic strain for the element, determined in advance. The cross section is assumed to remain plane, and so $\Delta \varepsilon_{k}=z_{k} \Delta k+\Delta \lambda$ in which $z_{k}$ is the coordinate of the element centroid in the direction normal to the axis of the bending moment, $\Delta k$ is the increment of curvature of the beam, and $\Delta \lambda$ is the increment of the uniaxial strain in the centroid of the cross section. According to the equilibrium conditions, the increments of the normal force $N$ and the bending moment $M$ about the centroidal axis of the beam are $\Delta N=$ $\sum_{k} A_{k} \Delta \sigma_{k}, \Delta M=\sum_{k} A_{k} z_{k} \Delta \sigma_{k}$ in which $A_{k}$ are the areas of the individual square elements (actually, they were all equal, $A_{k}=A$ ). Substituting here the foregoing expressions for $\Delta \sigma_{k}$ and $\Delta \varepsilon_{k}$, one obtains:

$$
\begin{aligned}
& \left(\sum_{k} A_{k} E_{k}^{\prime \prime} z_{k}^{2}\right) \Delta k+\left(\sum_{k} A_{k} E_{k}^{\prime \prime} z_{k}\right) \Delta \lambda=\Delta M+\Delta M^{\prime \prime}, \\
& \left(\sum_{k} A_{k} E_{k}^{\prime \prime} z_{k}\right) \Delta k+\left(\sum_{k} A_{k} E_{k}^{\prime \prime}\right) \Delta \lambda=\Delta N+\Delta N^{\prime \prime}
\end{aligned}
$$

$(\Delta N=0)$,

in which:

$$
\Delta M^{\prime \prime}=\sum_{k} A_{k} E_{k}^{\prime \prime} z_{k} \Delta \varepsilon_{k}^{\prime \prime}, \quad \Delta N^{\prime \prime}=\sum_{k} A_{k} E_{k}^{\prime \prime} \Delta \varepsilon_{k}^{\prime \prime} .
$$

These are the increments of the inelastic bending moment and the inelastic normal force, which are calculated in advance from the state in the previous time step or in the previous iteration of the current time step. For specimens without axial load, $\Delta N=0$. Equations (22) represent a system of two linear algebraic equations for the increments of curvature and axial strain, $\Delta k$ and $\Delta \lambda$. The deflection is calculated as:

$$
\delta=2 \int_{0}^{L / 2} k \bar{M} \mathrm{~d} x=\sum_{\beta} c_{\beta}(k \bar{M})_{\beta},
$$

in which $L=$ length of the beam (symmetric loading is assumed), $\bar{M}$ is the bending moment distribution produced by a unit loading in the sense of deflection $\delta$, and the summation represents a numerical integration formula with coefficients $c_{\beta}$; subscript $\beta$ refers to discrete cross sections, which are best chosen at Gauss integration points along the half-length of the beam, in which case $c_{\beta}=1$. Alternatively, the Simpson rule may be used. Only statically determinate beams are considered, so that $M$ and $N$ is known for each of the discrete cross sections.

To obtain the pseudo-elastic incremental stress-strain relation for the time step, the exponential algorithm derived in previous works (in references [3], [20]) for aging creep, and in reference [10] for strain-softening, is used. It is unconditionally stable and allows increasing the time step with the duration of loading, even if strain-softening occurs.

For the simultaneous integration of the diffusion equation, the time integration is done according to the Crank-Nicolson method ([51], [61]). The finite element matrix equations for the four-node square elements are formulated using the Galerkin method, same as implemented for concrete in program TEMPOR 2 described in reference [7]. The equivalent age $t_{\mathrm{e}}$ is also simultaneously incremented and stored for each finite element. The numerical algorithm is summarized in previous work [10].

It might be questioned whether cracking would not be better modeled by discrete cracks rather than strainsoftening. It has been shown [17], however, that for typical specimen sizes (thickness less than about two feet) shrinkage cracking cannot localize into distinct continuous cracks, due to stability conditions for a parallel crack system. It has also been concluded that, due to small crack spacing, the crack openings are so small (less than $0.1 \mathrm{~mm}$ ) that the cracks are discontinuous and transmit tensile stresses. Strain-softening is, therefore, more realistic than a discrete crack model. It is also more realistic than a stress-strain relation with a sudden stress drop [13], for which agreement with fracture test data cannot be attained. As for the well-known possible strain-localization instability caused by strain-softening [17], this is generally not a problem for typical test specimens because the tensile zone is restrained by an adjacent compression zone. 


\section{ANALYSIS OF TEST DATA}

\section{Determination of basic material data}

The compliance function $J\left(t, t^{\prime}\right)$ is determined from tests of sealed specimens loaded at different ages. The data, if available and complete, are then fitted with double power law, which is done automatically using program MATPAR [4]. This yields the five parameters of the double power law. Usually, however, the data are not sufficiently complete, especially with regard to the age at loading, $t^{\prime}$, and then the double power law is fitted with age exponent $m$ fixed in advance. For tests of limited duration, a fixed load duration exponent $m$ must also be used. If only the elastic modulus and the short-time data are available, then four out of five double power law parameters are predicted from composition and strength, and if no tests of sealed specimens (basic creep) are reported, all parameters are predicted from concrete strength and composition, as implemented in MATPAR [4]. The program then automatically calculates the relaxation times and the corresponding spring moduli $E_{\mu}$ as functions of age. Prediction of creep parameters from strength and composition involves, of course, considerable uncertainty ([15], [16]), which makes evaluation of drying tests somewhat ambiguous.

Creep tests of water-immersed specimens have sometimes been substituted for tests of sealed specimens. However, this introduces an error, sometimes larger, sometimes smaller, due to the fact that concrete imbibes water and swells. Swelling of the outer shell may produce tensile microcracks in the core. Some observations indicated appreciable differences in creep between sealed and water-immersed specimens: see for compression Powers [48], for tension Domone [28], and for torsion Ishai [38]. Properly, self-equilibrating stresses, microcracking due to swelling and water distribution need to be analyzed by finite elements, just like for drying specimens.

The parameters of the tensile strain-softening curve may be predicted from measured complete uniaxial tensile stress-strain curves [10]. This information is, however, usually unavailable. Then one may predict first the fracture energy as $G_{f} \simeq\left(2.72+0.0214 f_{t}^{\prime}\right) f_{t}^{\prime 2}$ $d_{a} / E$ where $d_{a}=$ maximum aggregate size, from which the average slope of the strain-softening segment is $E_{t} \simeq\left(E^{-1}-2 G_{f} / 3 d_{a} f_{t}^{\prime 2}\right)^{-1}[13]$.

\section{Creep tests at reduced constant water content}

Function $\varphi_{h}$ [equation (3)] could be directly determined from creep tests of specimens which were loaded after being dried to thermodynamic equilibrium at various humidities and were at constant humidity during creep. No study of drying creep involved such data, and, therefore, function $\varphi_{h}$ has to be inferred from other tests ([9], [53], [58]). In most of them, the predrying was made in an oven at $105^{\circ} \mathrm{C}$, to achieve equilibrium soon enough. However, heating in an oven involves a thermal strain about as large as the maxi- mum shrinkage, and, therefore, microcracks were likely produced. The same probably happened at subsequent rewetting to a desired relative humidity, as used in some tests. It seems that these undesirable side effects intensified the decrease of creep rate compared to never-dried specimens causing $\alpha_{h}$ to come out too small $\left(\alpha_{h} \simeq 1\right)$. Ideally one must use extremely thin specimens and lower the environmental humidity gradually and so slowly that the distribution of humidity throughout the wall thickness remains almost constant [17]. The only such tests seem to be those from reference [9], and they indicate a somewhat lower reduction of the creep rate due to a decreased water content, i.e. a larger $\alpha_{h} ; \alpha_{h} \simeq 0.5$, which has been used for the present computations.

\section{Shrinkage tests}

It has been generally assumed that these tests yield the material shrinkage parameters, but they do not, because of the nonhomogeneous stress state and microcracking. The tests must be analyzed by finite elements to obtain the true material properties, i. e., $\varepsilon_{s}^{0}$ [equation (5)]. An exception would be a shrinkage test of an extremely thin specimen in which the environmental humidity is decreased gradually and so slowly that the pore humidity distribution within the specimen remains almost uniform at all times ([9], [17]). But, a concrete specimen cannot be made sufficiently thin. Fortunately, it seems that one can generally use $f_{s}(h)$ $=1-h^{3}$ as a good approximation, and so only two parameters, $\varepsilon_{s}^{0}$ and $r$ [equations (5) and (14)], need to be determined in a trial-and-error manner.

Because the initial shrinkage deformation is very rapid, the first readings need to be taken right after exposure to the drying environment (within less than 1 minute), as found experimentally by $M$. Alou in Lausanne (private communication, 1983). In some reported tests such early readings might not have been made, in which case a constant unknown correction needs to be applied to all subsequent measured values.

Another difficulty arises with shrinkage tests in which the specimens are cured in water. Such specimens suffer nonuniform swelling that produces initial self-equilibrating stresses at the start of drying and initial microcracks in the core. Such tests are more difficult to evaluate (private communication, F. Wittmann, 1983, see also [41]).

\section{Compression creep during drying}

Twelve data sets, reported in references [23], [27], $[28],[31],[32],[33],[38],[44],[45],[47],[55],[56]$, have been considered. They involve basic creep data, shrinkage, and drying creep, except for [23], [28], [31], [37], [38], [47], which unfortunately omit the shrinkage data. References [33], [44], [45] involve only compression, references [28], [56] only tension, reference [37] only torsion, and references [31], [47] only bending. No data except references [23], [44] give experimental information on the age effect on creep, and none of these data 


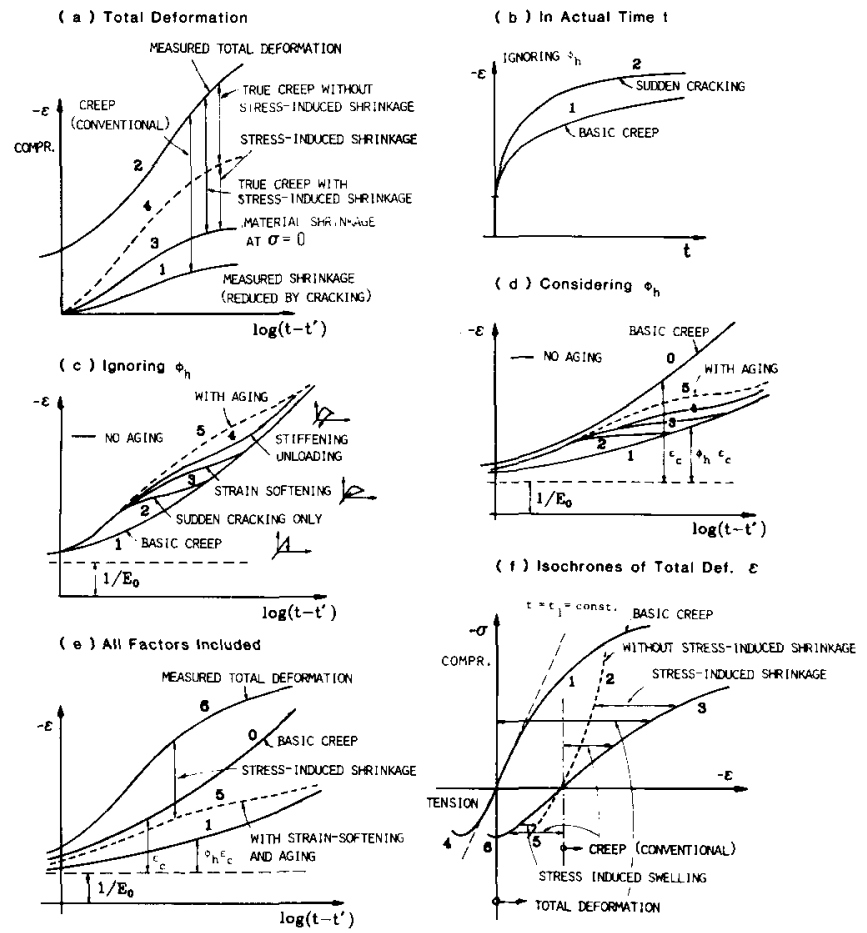

Fig. 3. - Influencing factors for drying creep.

include tensile strain-softening, not even direct tensile strength. Seven data ([23], [28], [32], [38], [44], [47], [56]) used water-immersed instead of sealed specimens in which case the computer program must initially analyze the stress distributions and cracking due to swelling during the water immersion period. In some data, the tensile creep tests were of very short duration (reference [28], up to 13 days).

Unlike the shrinkage specimens, the compressive creep specimens during drying typically suffer no tensile cracking (strain-softening) in transverse planes.

\section{Mechanism of drying creep and influencing factors}

By extensive computer fitting of essentially all relevant test data from the literature, it has been found that the principal mechanisms of drying creep, in their order of decreasing significance, are as follows:

(1) Stress-induced shrinkage [equations (14), (16)(20)], which represents a thermodynamic cross effect.

(2) Tensile cracking manifested by strain-softening.

(3) Irreversibility of unloading (i.e., resistance to contraction) after tensile cracking.

(4) Aging, i.e., increase of stiffness with age, unloading stiffness included.

These mechanisms are explained in figures 3 and 4 . As is illustrated by figure 4 , the observed specimen shrinkage is considerably less than the true material shrinkage between the cracks ( $f i g .3 a$ ). Because compression creep plus elastic deformation is determined by subtracting from the deformation of a loaded specimen the deformations of companion load-free specimen in the same environment, the observed (apparent) creep is significantly larger than that which would result by subtracting the true but unknown material shrinkage. If the stress-induced shrinkage is included (curve 4 in figure $3 a$ ), the true creep becomes still smaller.

If mechanisms 1, 3, and 4 (stress-induced shrinkage, unloading irreversibility, and aging) are ignored, along with the coefficient $\varphi_{h}$ (which describes the decrease of viscosities due to a lower water content), and if the strain-softening is modeled as a sudden stress drop to zero, then typically the curve in figure $3 b$ is obtained (when plotted in the actual time scale). From such results it might seem that a sudden stress drop due to cracking might alone suffice to explain the Pickett effect. Not so, however. When the same curve is plotted in $\log \bar{t}\left(\bar{t}=t-t^{\prime}=\right.$ load duration), the excess deformation (curve 2 in figure $3 c$ ) dies out after about one decade in the log-time scale. The excess deformation can be made to last considerably longer if the tensile strain-softening is considered as gradual (curve 3, fig. 3 c); however, the excess deformation eventually still vanishes. If one further includes irreversible unloading that does not return to the origin (figure 4, lines 4 and 7), the excess deformation never vanishes (curve 4 in figure $3 c$ ), and when the stiffening of unloading due to aging is included, the excess deformation is still more significant at long times (curve 5, figure $3 \mathrm{c}$ ). This is because in the later stage of drying, when the core of the specimen shrinks, the outer layer previously cracked in tension is forced to contract, which it resists (column $c$, lines 3-4, figure 4).

Thus, it might seem that factors 2-4 alone could explain the Pickett effect. The explanation is wrecked, however, if one includes (1) coefficient $\varphi_{h}$, i. e., the reduction of viscosities due to a reduced lower water content, and (2) the dependence of creep on stress ( fig. $3 d, f$ ).

With coefficient $\varphi_{h}$, the curves $2-5$ in figure $3 d$, which are in excess of curve 1 for steady-state creep of a specimen already in thermodynamic equilibrium at a certain reduced humidity, cannot be made to exceed the basic creep curve 0, no matter how the material parameters are chosen. This is one argument in support of the stress-induced shrinkage. Only then one can obtain curve 6 ( $f$ ig. $3 \mathrm{c}$ ) passing significantly above the basic creep curve 0 . An important aspect is that, because the stress-induced shrinkage [equation (14)] is defined incrementally and is not reversible, the excess deformation remains large for infinitely long times, while the contributions from tensile cracking or strainsoftening tend to die out ( fig. $3 \mathrm{c}$ ).

A second argument for stress-induced shrinkage comes from the stress-dependence of creep ( fig. $3 f$ ). Without the stress-induced shrinkage $(r=0 \quad$ in equation (14)), the isochrone for total deformation at drying (curve 2 in figure $3 f$ ) rises at an increasing slope, approaching the basic creep curve 1 at higher compressive stresses. By contrast, the existing tests [44] indicate isochrone 3 in figure $3 f$, which has a smaller slope than isochrone 1 for the basic creep, and which is diverging from the basic creep isochrone as the 
compressive stress magnitude increases. The reason that curve 2 ( fig. $3 f$ ) does not diverge from isochrone 1 for basic creep is that the contribution to excess deformation which is due to tensile cracking arises totally from the load-free companion shrinkage specimen, because the compression-loaded specimen does not crack (line 5 in figure 4). So this contribution is essentially constant, independent of stress, and a stressdependent contribution, as provided by the stress-induced shrinkage, is superimposed.

A third argument for the stress-induced shrinkage comes from tensile creep. The creep compliance in unixial tension is observed to be at least as large as that in uniaxial compression, and usually larger ([23], [27], [37]), which is true also at drying. This means that the Pickett effect is at least as intense in tension as in compression, and usually more intense (per unit stress). The part of the creep increase (per unit stress) due to cracking is larger for tension than for compression, according to the present theory, while the part due to coefficient $r$ is almost the same (per unit stress); see line 6 in figure 4 . Thus, the isochrone of total deformation (curve 6 in figure $3 f$ ) has a smaller slope than the basic creep isochrone in tension (curve 4). Without the stress-induced shrinkage, however, the total deformation isochrone at drying obtained from the computer program has about the same slope as the basic creep isochrone (curve 5). This is because the cracking caused by tensile loading in addition to the cracking caused
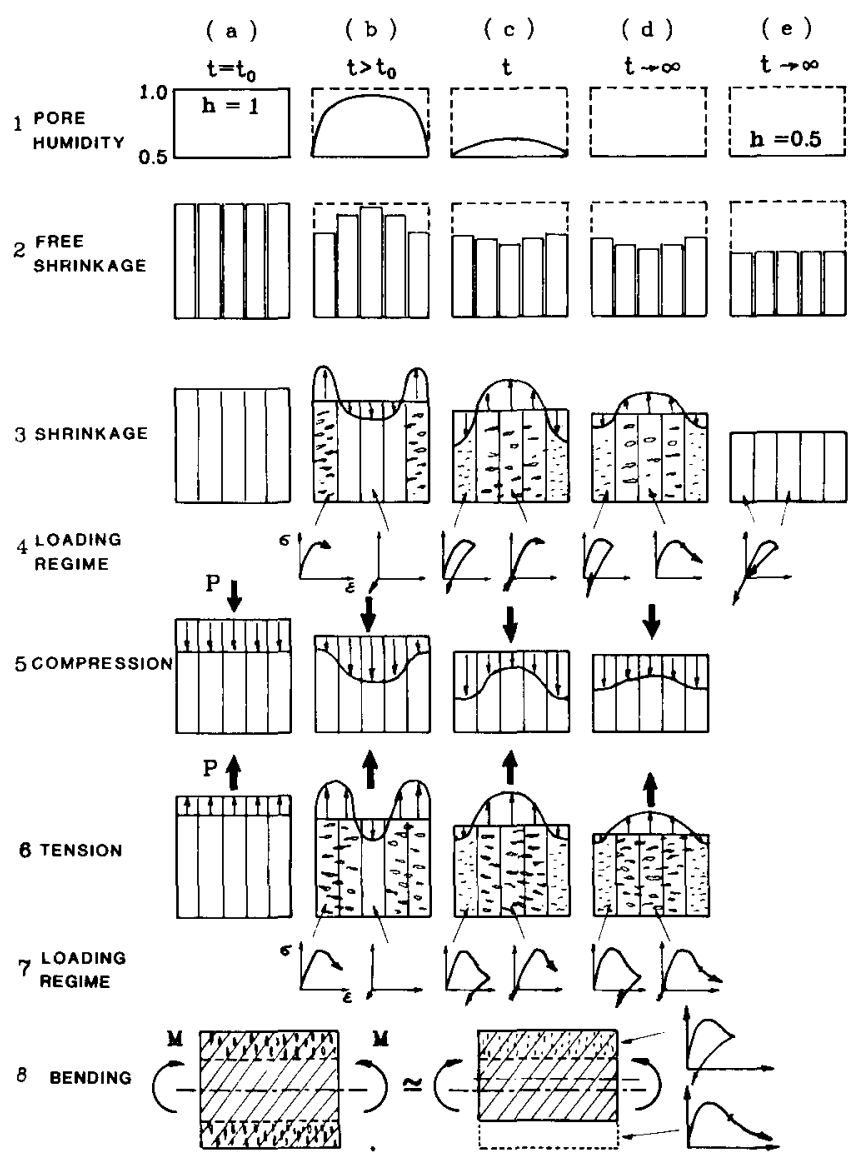

Fig. 4. - Sketch of stress states under various types of load. by shrinkage is not large enough, also because the additional cracking produced by tensile load does not increase much with time.

It may be noted in this context that, for concrete specimens immersed in water (which undergo swelling), the self-equilibrated stresses are opposite to those in line 3 of figure 4 . Yet, an increased creep is again observed during swelling ([28], [30]), which was initially considered paradoxical. However, it is not a paradox according to equation (14). Since tensile stress $\sigma$ reduces the value of the shrinkage (swelling) coefficient $\kappa$, the swelling in a tensile-loaded specimen is less than the swelling at no stress, thus making the deformation difference between the loaded and the load-free specimens larger. So, Domone's paradox [28] is simply explained by equation (14).

A fourth argument for the stress-induced shrinkage (or swelling) is provided by bending creep tests, by which the drying creep effect was in fact first unambiguously demonstrated by Pickett [47]. The bending creep test has the advantage that shrinkage (in a loadfree specimen) produces no bending, so that no companion specimen deformation needs to be subtracted. This eliminates the uncertainty due to inevitable random differences between two specimens, as well as the difficulty due to different cracking patterns and to different residual stress distributions in the loaded and the loadfree specimens whose deformations should be compared. Pickett [47] explained the excess creep deflections due to drying by nonlinearity of the tensile stress-strain diagram, with irreversible (elastic) unloading. Drying produces microcracked layers near the surface ( fig. $4 f$ ). As the bending moment, $M$, is introduced, the lower microcracked layer is further extended while the top microcracked layer is forced to contract back. The incremental stiffness for further extension is much less than that for reversed contraction. This is true even in Pickett's sense, without the strain-softening phenomenon (i. e., while the stress-strain relation has still a positive slope).

With strain-softening, however, the differences in incremental stiffness between the top and bottom microcracked layers are much more pronounced. The stronger effect provided by strain-softening with unloading irreversibility, and even more the phenomenon of stress-induced shrinkage (or swelling), are needed to fit the bending creep data due to drying while at the same time representing with the same model the compression and tension creeps during drying, for which sufficient data were unavailable to Pickett. As for the effect of stress-induced shrinkage, the compressed side of the beam has a higher shrinkage [due to equation (14)], and the tension side has a lower shrinkage than the true material shrinkage at no stress. Evidently, additional curvature (in effect, shrinkage warping) in the sense of the applied bending moment results. This appears to be the most important contribution of drying to the excess deflection.

Another test in which no comparison needs to be made with a companion shrinkage specimen is the 

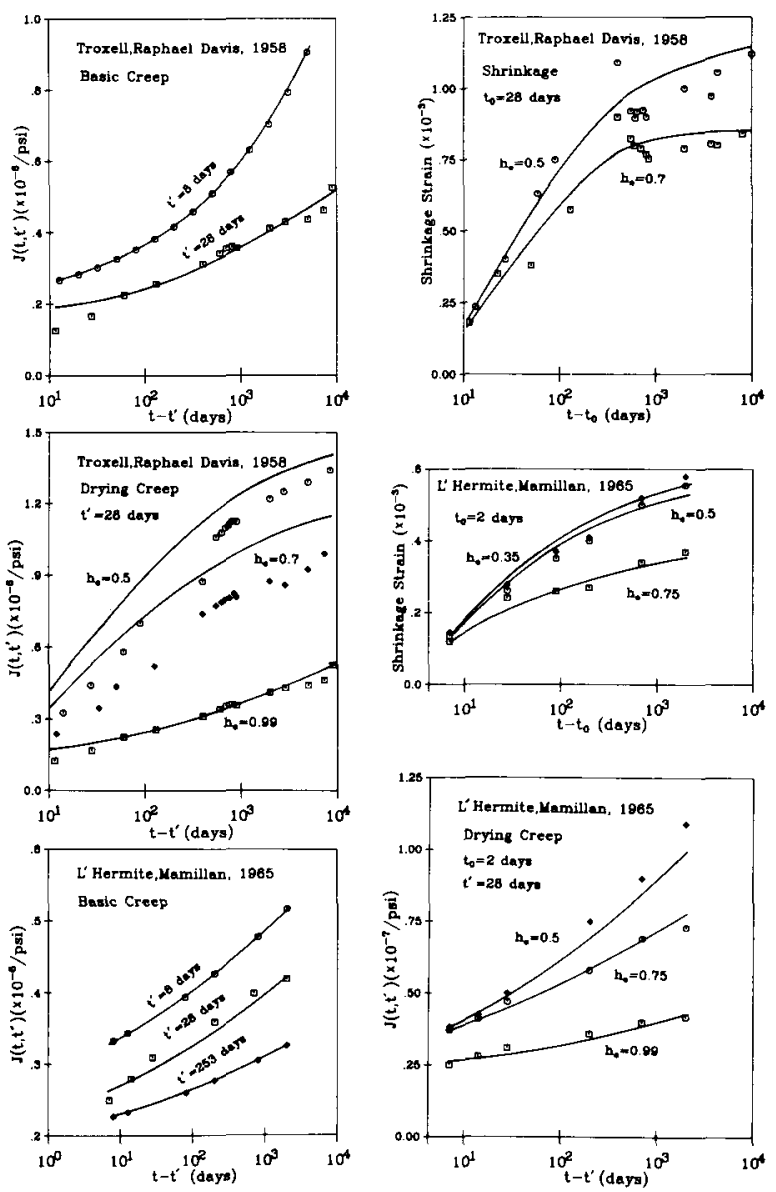

torsional creep test. We refrain, however, from analyzing torsional creep data [38] because a general model for tensile strain-softening is not yet available. In these tests, the direction of the principal tensile stress significantly rotates as the shrinkage stresses are being superimposed, and it is necessary to use for cracking (tensile strain-softening) a model which is tensorially invariant under the conditions of rotating principal stress directions. This is no easy task. Without such a model, no analysis of torsional creep tests can be sufficiently indicative.

In the past, numerous hypotheses have been advanced to explain drying creep. Perhaps the widest acceptance among practical experimentalists was gained by the seepage theory of Freyssinet and Lynam [42], used e. g., by Ruetz [53], and in a modified sense by Powers [48] who assumed creep to be caused by the movement of water, overall as well as local (between its different phases, i.e., capillary water, gel water or adsorbed water). Another widely accepted theory has been the viscous shear theory of Ruetz [53] which considered creep to be a result of shear sliding of the layered sheets only a few molecules thick in the cement gel. Feldman and Sereda [29] developed a microstructural model of hardened cement paste in which exit of water due to drying as well as superimposed compressive load was assumed to cause some sheets or layers to irreversibly stick together. Another hypothetical explanation in terms of changes in the interlayer space was proposed by Hope and Brown ([24], [34]). Ward and
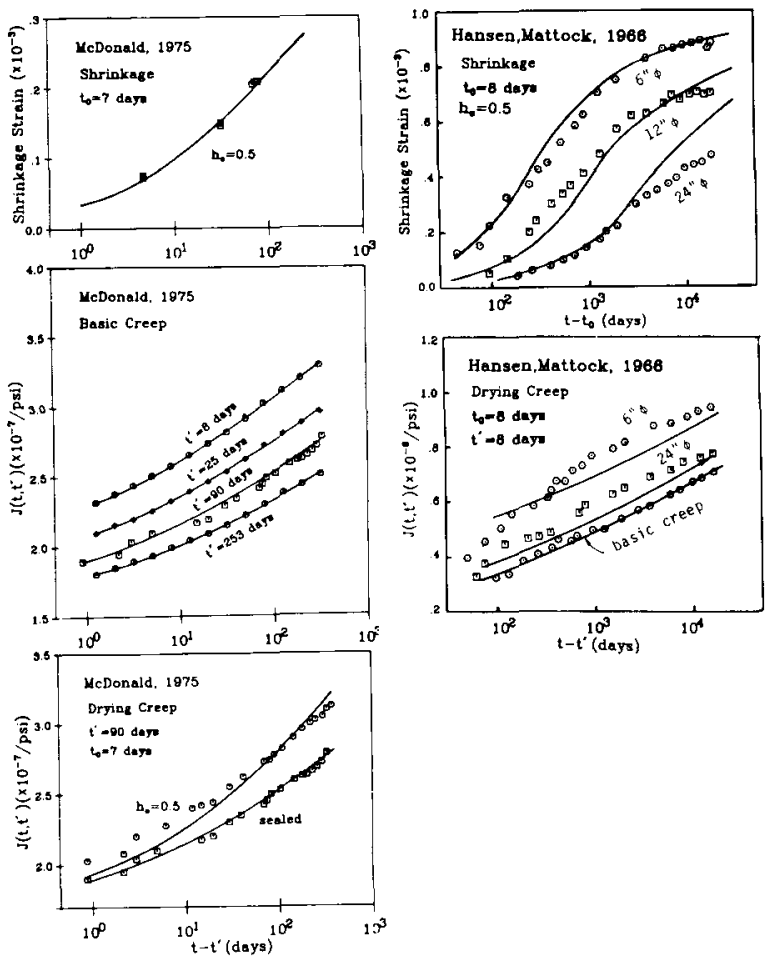

Fig. 5. - Fits of drying creep data for compression. (a) Troxell et al.; (b) L'Hermite and Mamillan; (c) McDonald; (d) Hansen and Mattock.

Cook [56] enhanced the seepage theory by proposing that a time-dependent delayed development of microcracks contributes to the excess deformation in tensile creep caused by drying. Brooks and Neville [23] sought explanation of the excess creep in tension and compression by a combination of the seepage and viscous shear theories.

It is difficult to argue for or against these previous hypotheses because they have never been formulated mathematically so that it is not sufficiently clear what was really meant. Nevertheless, due to the idea of microdiffusion, some sort of the seepage theory might be considered to be involved in our mathematical model, and due to the equivalence of the stress-induced shrinkage with the dependence of viscosity on $h$, some sort of the viscous shear theory seems to be also involved. So does Ward and Cook's microcracking, but not only as a mechanism for tensile creep but also for compression creep, as mathematically introduced by Bažant and $\mathrm{Wu}$, Bresler and Iding, and Wittmann and Roelfstra ([19], [36], [60]). Power's idea [49] of thermodynamic equilibrium of hindered adsorbed water and capillary water is also part of the present theory.

Fits of the most important test data from the literature ([23], [33], [44], [45], [47], [55], [56]) achieved with the present theory are shown as the solid curves in figures 5 and 9. They include shrinkage, basic and drying creep in compression ( fig. 5), tensile drying creep ( fig. 7) and bending creep ( fig. 9). To aid 


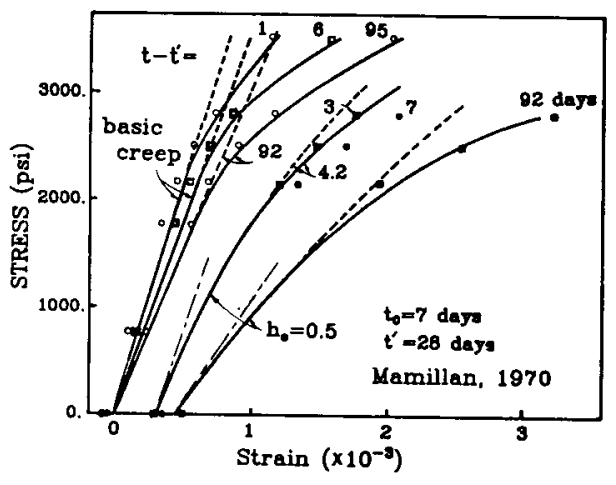

Fig. 6. - Fits of creep isochrones measured by Mamillan (Solid lines - with nonlinearity modification, dashed lines - without modification).

understanding, some typical calculated stress distributions at various times within the test specimens are plotted in figures 8 and 10 . These distributions are quite similar to those reported by Bažant and $\mathrm{Wu}$ [19], which is reassuring due to the similarity of the theoretical model. Knowledge of these results was used in explanations based on figures 3 and 4 . Note the reversals of the residual stress profiles between the short and long times in figures 8 and 10. The material parameters for these data are indicated in the figures. Essential information on the test data used is summarized in appendix III, along with the values of further material parameters and properties used in data fitting (experimental information that is lacking is pointed out and the method used to deduce this information indirectly is indicated).

Since, in bending creep during drying, the tensile face layer nearly looses its stiffness, while the drying layer at the compression face does not, the incremental stiffness becomes distributed asymmetrically with regard to the beam axis, as if the tensile face drying layer were removed. Therefore, the neutral axis moves during drying creep upwards, causing that there must be an extension along the initial beam axis. However, no attempt to measure this has been reported.

Based on fitting of Brooks and Neville's test data, the tensile drying creep is larger than the compressive drying creep, and the present model agrees ( fig. 7). For bending data, figure $9 c, d, f$ gives the central deflection of a simply supported beam. Figure $9 c$ shows the results for deflection obtained by various loading conditions (line $a$-loaded and drying; line $b$-loaded not drying; line $c$-drying not loaded). Figure $9 d$ demonstrates the effect of coefficient $r$ and various degrees of cracking, i. e., strain-softening, $\left(r=0.3 / f_{t}^{\prime}\right.$, softening parameters in equation $27 a$ of reference [10] are $E_{s}=1.58 \times 10^{8}, s=0.3$, and $c$ is given in figure $9 e)$. Line $d(c=0)$ indicates the elastic states. When strain-softening coefficient $c \geqq 78$, the beam develops cracking already at very small strains and then $\delta_{c r}$ becomes very large. The choice $c=55$ appears to provide about the correct tensile peak stress point ( fig. $9 e$ ) and line $b$ in figure $9 d$ is obtained.

Figure $9 f$ shows the effect of various values of $r$ on the deflection of a loaded-drying beam. Figure $9 \mathrm{~g}$ gives the axial elongation obtained at the center of the beam for different loading conditions (lines $a, b, c$ are defined in figure $9 c$, line $d$ represents the hypothetical response of a loaded drying beam at no cracking). Figure $9 h$ illustrates the axial elongation (shortening) due to shrinkage $\left(b, c, d\right.$ corresponds to $r=0.3 / f_{t}^{\prime}, 0.6 / f_{t}^{\prime}$ and
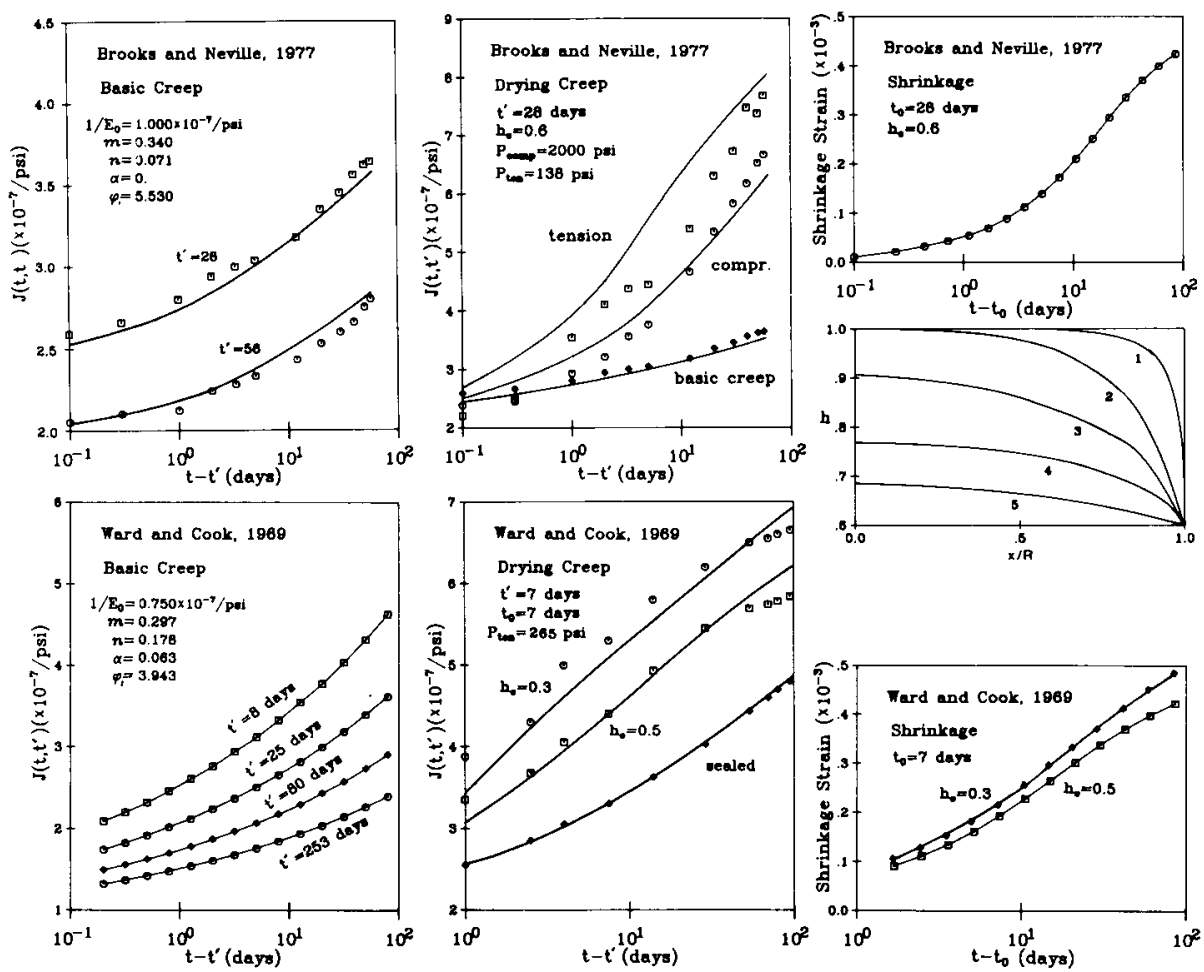

Fig. 7. - Fits of drying creep in tension. (a) Brooks and Neville; (line 1, $t-t^{\prime}=1$ day; line 2, 7.5 days; line 3, 30 days; line 4, 85 days; line 5 , 242 days); (b) Ward and Cook; (c) moisture profiles. 

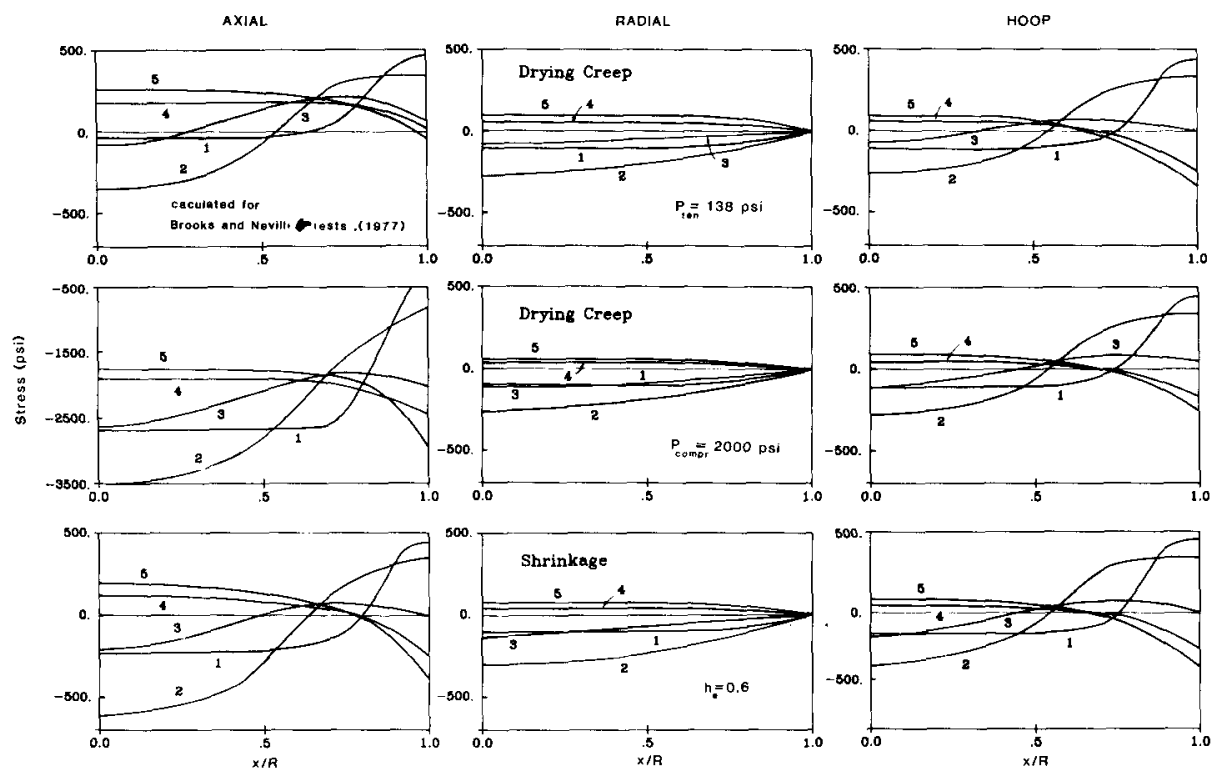

Fig. 8. - Stress distributions calculated for Brooks and Neville's test. $(a)$ tensile test; $(b)$ compressive test; $(c)$ strinkage.

0 , respectively). These two figures show that cracking can reduce the magnitude of axial shortening; $r$ has little effect on the shortening of a drying concrete beam without bending moment. For a sealed beam, the axial elongation is of course theoretically zero.

It is also of interest of note that small size specimens with a large diffusivity experience reloading after strainsoftening. For the case of strain-softening, or for tensile loading, the tensile stress build-up is then very fast in the central core. The tensile strain soon exceeds the peak stress point and strain-softening takes place at the central core. To preserve equilibrium, reloading is therefore produced in the outer shell of the specimen, as illustrated in lines 4 and 7 , column $d$ of figure 4 . Figure 10 shows the calculated axial stress distributions in the midspan cross section of the beam tested by Pickett. The distributions in the horizontal direction of the tensile face are at the left, and the distributions in the vertical direction (direction of load) at the side face and at the center plane of the beam are at the right.

History of the researches on creep at drying teaches us that limited test data can be explained in more than one way, sometimes using radically different theories. The interpretation of test data becomes unambiguous only when the complete set of information on the material is considered. The present study analyzes almost as complete a set of test data as can be obtained at the present. A satisfactory agreement is achieved for all the diverse test types using one and the same mathematical model and consistent values of material parameters. The essential aspects of creep at drying now appear to be reasonably well understood and predictable.

\section{CONCLUSIONS}

1. The Pickett effect, i. e., the apparent increase of creep caused by simultaneous drying, cannot be explained solely as a constitutive property of the material. A significant contribution arises from the selfequilibrated residual stress states which are governed by the boundary conditions and depend on the solution of the diffusion equation for drying.

2. There are four significant sources of the Pickett effect. In their order of decreasing significance, these are:

(1) stress-induced shrinkage [equation (14)];

(2) tensile strain-softening due to progressive cracking;

(3) irreversible unloading after tensile strain-softening;

(4) increase of the material stiffness due to aging.

3. The present theory explains, in a consistent manner, all the presently known experimental facts. In particular, one and the same theory with consistent parameter values can fit the data on basic creep, creep of specimens with reduced water content in hygral equilibrium, shrinkage, swelling, and creep at drying in compression, tension, and bending. Besides, the strainsoftening properties assumed also agree with concrete fracture tests, direct tensile tests, deflections tests of cracked reinforced beams, and crack shear tests.

4. The present theory is a special case of a previously advanced thermodynamic theory ([5], [6], [8], [19]), except for the fact that a sudden stress drop due to cracking is generalized to gradual strain-softening with irreversibility. The present special case avoids all the hypothetical features of that earlier theory and does not invoke any of the various specific assumptions about creep mechanism and cement paste microstructure made in that theory.

5. From the microstructural viewpoint, the present theory rests on only one hypothesis, namely that there exists some mechanism causing the viscosity coefficients which characterize the creep rate to depend on the 

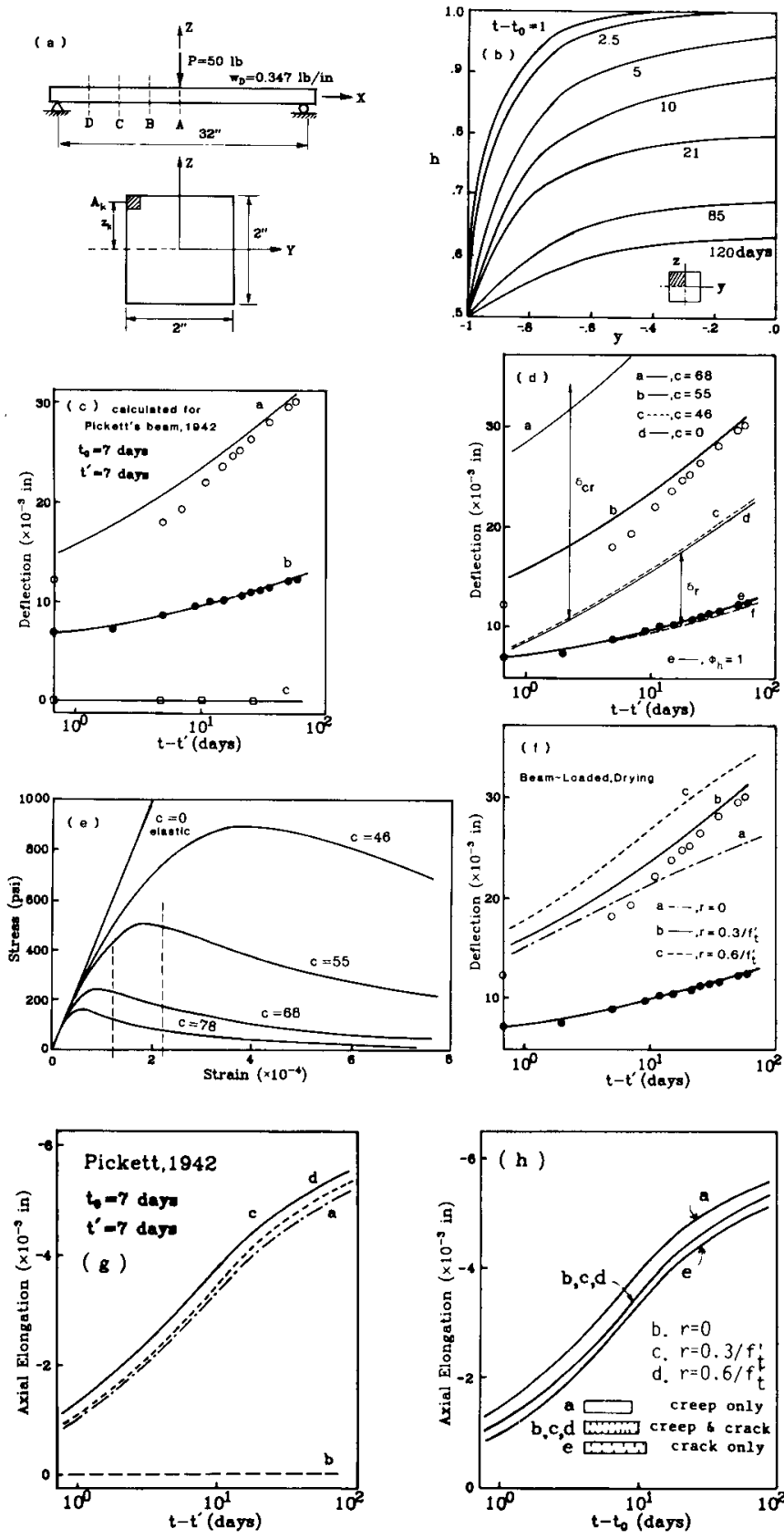

Fig. 9. - Fits of Pickett's drying creep tests in bending. (a) load and size of beam; $(b)$ moisture profile; $(c),(d)$ central deflection; (e) various types of stress-strain curves, $(f)$ effect of $r$ on drying creep, $(g),(h)$ axial elongation.

magnitude of the flux of the local microdiffusion of water between the macropores (capillary pores) and the adjacent micropores in the cement gel (gel pores, hindered adsorbed layers, interlayer spaces).

6. The mathematical formulation is drastically simplified by further assuming that the half-time of the aforementioned microdiffusion process is negligibly short compared to the drying half-time of any practical concrete specimen or structure, i. e., the microdiffusion is infinitely fast. Then the aforementioned hypothesis reduces to a dependence of the viscosity coefficients on the time rate of change of pore humidity (or water content). This is, however, equivalent to stress-induced shrinkage a phenomenon in which the ratio of the shrinkage strain increment to the pore humidity increment depends on stress. The viscosities may then be treated as if they were independent of the pore humidity rate.

7. It appears sufficient to assume that the shrinkage coefficient depends on stress linearly [equation (14)]. In three dimensions, the shrinkage coefficient becomes a tensor which is such that the stress-induced shrinkage in a certain direction does not depend on the transverse normal stresses.

8. If there is stress-induced shrinkage, there must also be stress-induced thermal expansion (or contraction) [equation (14)]. This follows from the fact that the difference in chemical potentials of water driving the microdiffusion must depend not only on pressures but also on temperature. This probably explains the transitional thermal creep.

9. Tensile cracking alone cannot explain the apparent creep increase caused by drying simultaneous with loading. This effect is short-lived, as can be seen from plots in log-time scale, and gives an incorrect dependence of the drying creep isochrones on stress. However, for tensile and bending creep, the contributions from tensile cracking alone are dominant, and stronger than the contribution of stress-induced shrinkage, as compared to compressive creep per unit stress.

10. Consideration of gradual strain-softening instead of a sudden stress drop extends the contribution of cracking to the excess creep into longer time periods, however, the contribution still dies out at longer times unless one further takes into account that unloading (i. e., contraction) after tensile cracking is irreversible, and that the material undergoes aging. Nevertheless, even with all these contributions, the effect of tensile cracking generally does not overcome the reduction of creep due to the increase of viscosity coefficients caused by a decrease of water content. This opposite tendency from the viscosity coefficients can be overcome only by introducing stress-induced shrinkage into the mathematical model.

11. Compared to the existing creep model, the present theory requires introducing one additional material
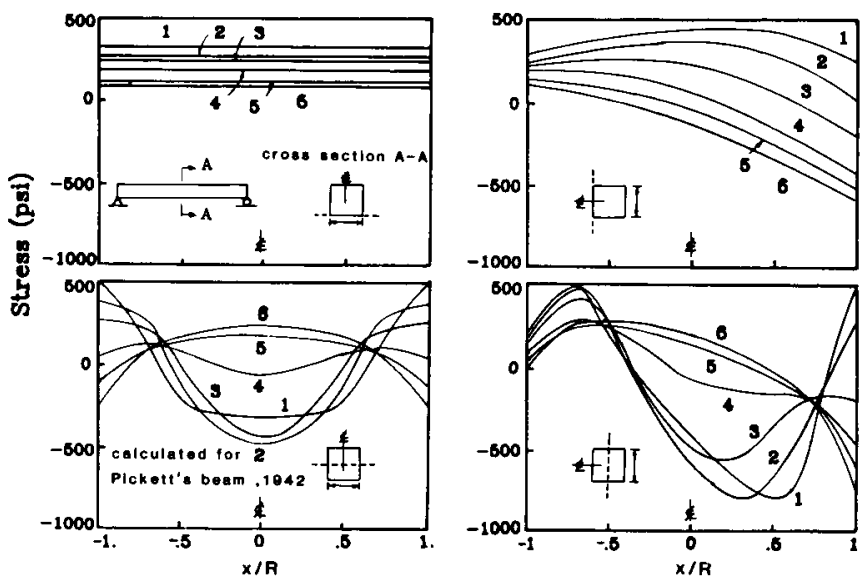

Fig. 10. - Calculated axial stress: distributions at the midspan of Pickett's beam (line $a$ in figure $9 \mathrm{c}$ ) (curve $1, t-t^{\prime}=0.1$ day; 1 , 1.2 days; $3,5.2$ days; $4,10.6$ days; 5,30 days; 6,60 days). 
parameter ( $r$ ) for the stress-induced shrinkage, and three additional parameters for tensile strain-softening.

12. Pickett's original explanation, relying on irreversibility of non-linear hardening tensile behavior, is in essence correct but incomplete; it neglects other physical sources of the phenomenon (unknown at Pickett's time), which are actually more important, especially for loading modes other than bending.

\section{Acknowledgement}

Financial support under US National Science Foundation Grant No. CEE800-3148 to Northwestern University is gratefully acknowledged. Thanks are due to Mary Hill for her outstanding secretarial assistance.

\section{APPENDIX I}

\section{Summary of strain-softening model}

For the reader's convenience we summarize the strain softening model from reference [10]. The tensile cracking is permitted to occur only in three orthogonal directions which are fixed when the maximum principal stress first attains the tensile strength value. This restriction avoids the difficult question of interaction between microcracks forming skew angles with each other. The $(6 \times 1)$ column matrix of total strain is expressed as $\varepsilon=\mathbf{e}+\xi+\varepsilon^{0}$ in which $\mathbf{e}=$ strain due to elastic deformation plus creep, $\varepsilon^{0}=$ sum of strinkage and thermal strains, and $\xi=$ additional smoothed-out averaged strain due to cracking which results in strain softening. For direction $x_{1}$ normal to one crack system, the strain softening is described by an algebraic stress-strain relation:

$\sigma_{11}=C\left(\xi_{11}\right) \xi_{11} \quad(11 \rightarrow 22 \rightarrow 33)$,

while for directions $x_{2}$ and $x_{3}$ the relations are obtained by subscript permutations. The secant strain softening modulus $C$ may be considered as

$C\left(\xi_{11}\right)=E_{s} e^{-c \xi_{11}^{s}}$

or

$C\left(\xi_{11}\right)=B_{s} \xi_{11}^{q-1} e^{-c \xi_{11}^{s}} \quad(0<q \leqq 1)$,

in which $c, s, q$, and $B_{s}$ or $E_{s}$ are four empirical constants of the material, to be determined most conveniently from complete stress-strain curves from direct tensile tests.

Formulation of a time-step algorithm for strain softening, which is stable and accurate even for very large steps, is a tricky proposition. The objectives can be met by the following formulas, called the exponential algorithm for strain softening [10]:

$\Delta \xi=\mathbf{B}^{C} \Delta \boldsymbol{\sigma}+\Delta \xi^{\prime \prime}$, in which $\mathbf{B}^{C}$ is a square $(6 \times 6)$ matrix whose elements are all zero except for the first three diagonal elements which are $D_{11}^{-1}, D_{22}^{-1}, D_{33}^{-1}$, and

$$
\begin{aligned}
& D_{11}=\frac{1}{\Delta z_{11}}\left(1-\mathrm{e}^{-\Delta z_{11}}\right) C_{11_{r+1 / 2}} \\
& \Delta \xi_{11}^{\prime \prime}=\left(1-\mathrm{e}^{-\Delta z_{11}}\right) \frac{\sigma_{11_{r}}}{D_{11}}
\end{aligned}
$$

Here $r$ refers to time step $(r, r+1)$, and subscript $r+1 / 2$ refers to the midstep; and $\Delta z_{11}=-\Delta C_{11} / C_{11_{r+1 / 2}}$. Matrix $\mathbf{B}^{C}$ represents the incremental elastic stiffness matrix for strain softening, and the column matrix $\Delta \xi^{\prime \prime}$ represents the inelastic strain increments due to strain softening.

For linear aging creep based on the Maxwell chain model, the incremental stress-strain relation, which is best formulated according to a previously published exponential algorithm ([3], [5], [20]), may be written in the pseudo-elastic form $\Delta \mathbf{e}=\mathbf{B}^{M} \Delta \boldsymbol{\sigma}+\Delta \mathbf{e}^{\prime \prime}$, in which $\mathbf{B}^{M}$ is a certain $(6 \times 6)$ square matrix, different for each time step, and $\Delta \mathbf{e}^{\prime \prime}$ is the column matrix of inelastic strain increment due to creep. Combining this relation with equation (24), one obtains the overall incremental pseudo-elastic stress-strain relation for the material:

$\Delta \varepsilon=\mathbf{D} \Delta \varepsilon+\Delta \varepsilon^{\prime \prime}$,

in which:

$\mathbf{D}=\mathbf{B}^{M}+\mathbf{B}^{C}, \quad \Delta \varepsilon^{\prime \prime}=\Delta \mathbf{e}^{\prime \prime}+\Delta \xi^{\prime \prime}+\Delta \varepsilon^{0}$.

Equation 27 is then used in each time step of the finite element program described here. This algorithm permits using time steps that increase in a geometric progression, same as for aging creep without strain softening. This is possible without a large loss of accuracy even if the tensile strain softening happens quite rapidly after many years of creep.

The unloading and reloading behavior after tensile strain softening is also rather important to model the Pickett effect. This behavior was assumed to be significantly irreversible, with an unloading diagram that does not return to zero strain at zero stress [10]. This was accomplished by assuming the tangent modulus at unloading to be the same as the secant modulus for loading at the same value of strain. This assumption agrees reasonably well with the recent measurements of Reinhardt and Cornelissen (Cement and Concrete Research, 1984).

\section{APPENDIX II}

\section{Relation to BP model for present formulation}

It may be of interest to note that the present formulation simplifies to the form of creep compliance used in the previously developed practical prediction model ([15], [16]). Consider the case of constant uniaxial stress 
$\sigma$. Then:

$\mathrm{d} \varepsilon_{s}=\kappa \mathrm{d} h=\varepsilon_{s}^{0} \psi(1-r \sigma) \mathrm{d} h=\mathrm{d} \varepsilon_{s}^{\prime}+\mathrm{d} \varepsilon_{s}^{*}$,

in which $\varepsilon_{\mathrm{s}}^{\prime}=\int \varepsilon_{\mathrm{s}}^{0} \psi \mathrm{d} h=$ stress-independent shrinkage, with:

$C_{d}\left(t, t^{\prime}\right)=-r \varepsilon_{s}^{0} \int_{t^{\prime}}^{t} \psi \mathrm{d} h\left(t^{\prime \prime}\right)$

which is positive for drying since $\mathrm{d} h<0$. The total deformation, therefore, is:

$\varepsilon(t)=\sigma\left[J_{0}\left(t, t^{\prime}\right)+C_{d}\left(t, t^{\prime}\right)\right]$

in which $J_{0}\left(t, t^{\prime}\right)$ is the compliance function for constant humidity, and $C_{d}\left(t, t^{\prime}\right)$ is the additional compliance due a change in humidity. This has the same structure as the compliance function used in BP Model ([15], [16]).

\section{APPENDIX III}

\section{Basic informations on test data used}

\section{Troxell, Raphael and Davis (1958) [55]}

Cylinders $4 \times 14$ in $(102 \times 356 \mathrm{~mm}), 70^{\circ} \mathrm{F}\left(21^{\circ} \mathrm{C}\right), 28$ day cylinder strength 2,500 psi $\left(17.2 \mathrm{~N} / \mathrm{mm}^{2}\right)$, cement type I, water-cement-sand-aggr. $=0.59: 1: 2: 3.67$; loading $\sigma$ (comp.) $=800 \mathrm{psi}, E_{s}=1 \times 10^{7} \mathrm{psi}, c=1,432$, $s=0.7 ; \quad C_{0}=7.74 \mathrm{~mm}^{2} /$ day, $\quad \varepsilon_{s}^{0}=0.0017, \quad r=0.4 / f_{i}^{\prime}$; use typical values for diffusivity, $\alpha_{0}=0.05, h_{c}=0.75$, $n=6 ;$ coefficients of double power law: $E_{0}=5.69 \times 10^{6} \mathrm{psi}, m=0.873, n=0.3452, \alpha=0.016$, $\varphi_{1}=1.212 ; \tau_{1}=0.333$ day, 7 chain units.

\section{L'Hermite, Mamillan (1965) [41]}

Prisms $7 \times 7 \times 28 \mathrm{~cm}, 68^{\circ} \mathrm{F}\left(20^{\circ} \mathrm{C}\right), 28$-day cylinder strength $5,365 \mathrm{psi}\left(34.8 \mathrm{~N} / \mathrm{mm}^{2}\right)$, water-cement-sandaggr. $=0.49: 1.0: 1.75: 3.07 ; \quad P \quad$ (comp.) $=1,422 \quad$ psi, $E_{\mathrm{s}}=1 \times 10^{7} \mathrm{psi}, c=1,432, \mathrm{~s}=0.7, C_{0}=3.95 \mathrm{~mm}^{2} / \mathrm{day}$, $\varepsilon_{s}^{0}=0.001, \quad r=0.8 / f_{t}^{\prime} ; \quad E_{0}=1 \times 10^{7} \quad$ psi, $\quad m=0.243$, $n=0.106, \alpha=0.148, \varphi_{1}=2.487$.

\section{McDonald (1975) [45]}

Cylinders $6 \times 16$ in $(152 \times 406 \mathrm{~mm}), 73^{\circ} \mathrm{F}\left(23^{\circ} \mathrm{C}\right)$, 28 -day cylinder strength $7,320 \mathrm{psi}\left(50.5 \mathrm{~N} / \mathrm{mm}^{2}\right)$, cement type II, water - cement - sand aggr. $=0.425: 1: 2.03: 2.62$; aging information obtained by BP model, $\sigma$ (comp.) $=2,400$ psi, $E_{s}=1 \times 10^{7} \mathrm{psi}, c=1,432, s=0.7 ; C_{0}=9.03 \mathrm{~mm}^{2} / \mathrm{day}$, $\varepsilon_{s}^{0}=0.00055, \quad r=0.57 / f_{t}^{\prime} ; \quad E_{0}=2 \times 10^{7} \mathrm{psi}, \quad m=0.218$, $n=0.077, \alpha=0.56, \varphi_{1}=3.015$.

\section{Hansen and Mattock, 1966 [33]}

Cylinders (lengths of cylinders of 10 to $61 \mathrm{~cm}$ dia. are $457,559,660,864,1,067,1,270,1,473 \mathrm{~mm}), 70^{\circ} \mathrm{F}$ $\left(21^{\circ} \mathrm{C}\right)$, 28-day cylinder strength $6,000 \mathrm{psi}$ $\left(41.4 \mathrm{~N} / \mathrm{mm}^{2}\right)$, cement type III, water-cementsandaggr. $=.71: 1: 3.3: 2.7 ; \quad \sigma \quad$ (comp.) $=1,200 \mathrm{psi}$, $E_{s}=1 \times 10^{7} \mathrm{psi}, \quad c=1,432, \quad s=0.5$; $C_{0}=15.80 \mathrm{~mm}^{2} / \mathrm{day}, \quad \varepsilon_{s}^{0}=0.0012, \quad r=0.17 / f_{t}^{\prime}$; $E_{0}=2 \times 10^{7} \mathrm{psi}, \quad m=0.0801, \quad n=0.190, \quad \alpha=0.333$, $\varphi_{1}=2.224$; Aging information obtained by BP model.

\section{Brooks and Neville, 1977 [23]}

Cylinders $3 \times 10$ in $(76 \times 255 \mathrm{~mm}), 71.6^{\circ} \mathrm{F}\left(22^{\circ} \mathrm{C}\right)$, 28 -day cylinder strength, $6,400 \mathrm{psi}\left(44.2 \mathrm{~N} / \mathrm{mm}^{2}\right)$, $28-$ day tensile strength $=462 \mathrm{psi}\left(3.19 \mathrm{~N} / \mathrm{mm}^{2}\right)$, cement type I, water-cement-sand-aggr. $=0.5: 1.0: 2.0: 4.0$; $\sigma($ ten. $)=138 \mathrm{psi}, \sigma($ comp. $)=2,000 \mathrm{psi}, E_{s}=1 \times 10^{7}$, $c=1,432, \quad s=0.7 ; \quad$ (no shrinkage data), predicted $C_{0}=7.74 \mathrm{~mm}^{2} / \mathrm{day}$ and $\varepsilon_{\mathrm{s}}^{0}=0.0008, \quad r=0.27 / f_{t}^{\prime}$, $E_{0}=1 \times 10^{7}, m=0.34, n=0.071, \alpha=0, \varphi_{1}=5.530$.

\section{Ward and Cook, 1969 [56]}

Prisms $\quad 4^{\prime \prime} \times 6^{\prime \prime} \times 20^{\prime \prime}, \quad 77^{\circ} \mathrm{F} \quad\left(25^{\circ} \mathrm{C}\right), \quad 28$-day strength $=7,700 \mathrm{psi}$; cement-type III, watercementsand-aggr $=0.4: 1.0: 3.0 ; \quad$ ave. tensile strength $=530$ psi, $\sigma$ (ten.) $=265$ psi; $E_{s}=1 \times 10^{7}$ psi, $c=1,432, \quad s=0.7 ; \quad$ (no shrinkage data), $C_{0}=7.75 \mathrm{~mm}^{2} /$ day and $\varepsilon_{s}^{0}=0.008, \quad r=0.17 / f_{t}^{\prime}$; $E_{0}=1.333 \times 10^{7} \mathrm{psi}, m=0.297, n=0.178, \alpha=0.063$, $\varphi_{1}=3.943$ (from BP model).

\section{Pickett, 1942 [47]}

Beams with 2 in by 2 in cross section and 32 in span, the load consisted of weight of the beam and a fiftypound force at the center of the beam is causing the moments $-444.4,-341.6,-233.3$ and $-119.41 b$ in to be applied at cross sections $A, B, C$, and $D$ respectively; water-cement-sand-aggr. $=0.5: 1.0$ : $2.08: 2.42 ; E_{s}=1.58 E 8, c=55, s=0.3$; (no shrinkage data), predicted $\varepsilon_{\mathrm{s}}^{0}=0.000,8$, and $C_{0}=6.45 \mathrm{~mm}^{2} /$ day, $r=0.30 / f_{t}^{\prime}$.

\section{TABLE}

MODULi ( $10^{6} \mathrm{psi}$ ) AND RELAXATION TIMES (DAYS) FOR MAXWELl CHAiN

\begin{tabular}{|c|c|c|c|c|c|c|c|}
\hline \multirow{2}{*}{$t^{\prime}$} & \multicolumn{7}{|c|}{$\tau_{\mu}=$} \\
\hline & 0.33 & 3.3 & 33 & 333 & 3,333 & $3.3 \times 10^{4}$ & $1 \times 10^{30}$ \\
\hline $\begin{array}{l}8 \ldots \ldots \\
25 \ldots \ldots \\
80 \ldots \ldots \\
253 \ldots \ldots \\
800 \ldots \ldots \\
2,529 \ldots \ldots \\
\ldots\end{array}$ & $\begin{array}{l}1.46 \\
1.61 \\
1.68 \\
1.65 \\
1.55 \\
1.55\end{array}$ & $\begin{array}{l}1.27 \\
1.39 \\
1.51 \\
1.58 \\
1.58 \\
1.58\end{array}$ & $\begin{array}{l}1.23 \\
1.27 \\
1.35 \\
1.46 \\
1.54 \\
1.54\end{array}$ & $\begin{array}{l}1.47 \\
1.39 \\
1.36 \\
1.37 \\
1.44 \\
1.44\end{array}$ & $\begin{array}{l}1.81 \\
1.68 \\
1.57 \\
1.47 \\
1.43 \\
1.43\end{array}$ & $\begin{array}{l}2.16 \\
2.00 \\
1.82 \\
1.62 \\
1.47 \\
1.47\end{array}$ & $\begin{array}{r}-3.33 \\
-2.09 \\
-0.36 \\
0.31 \\
1.36 \\
1.36\end{array}$ \\
\hline
\end{tabular}

\section{REFERENCES}

[1] Ali I., KeSLeR C. - Mechanisms of creep in concrete. ACI Special Publication SP-9, 1964, pp. 35-37.

[2] BažanT Z. P. - Constitutive equation of wood at variable humidity and temperature. Wood Science and Technology (Springer Verlag), in press. 
[3] BAžAnt Z. P. - Mathematical models for creep and shrinkage of concrete. Chapter 7 in Creep and shrinkage in concrete structures. BAZANT Z. P., WITTMANN F. H., Eds, John Wiley and Sons, 1982, pp. 163-256.

[4] BAZ̆ANT Z. P. - Input of creep and shrinkage characteristics for a structural analysis program. Materials and Structures, RILEM, Paris, Vol. 15, No. 88, 283-290, 1982.

[5] BAZ̆ANT Z. P. - Theory of creep and shrinkage in concrete structures: a precis of recent developments. Mechanics Today, Vol. 2, pp. 1-93, Nemat-Naser S., Ed., John Wiley, New York, 1975.

[6] BAŽANT Z. P. - Thermodynamics of interacting continua with surfaces and creep analysis of concrete structures. Nuclear Engrg. and Design, Vol. 20, 1972, pp. 477-505; see also Cem. Concr. Res., 2, Vol. 2., 1972, pp. 1-16.

[7] BAŽANT Z. P. - Thermodynamic theory of concrete deformation at variable temperature and humidity. Report 69-11, Div. Struc. Engrg. and Struct. Mech., Univ. of California, Berkeley, Aug. 1969; see also Amer. Concr. Inst. Spec. Publ., No. 27, 1971, pp. 411-427.

[8] BAZ̆ANT Z. P. - Constitutive equation for concrete creep and shrinkage based on thermodynamics of multiphase systems, Materials and Structures, RILEM Paris, Vol. 3, 1970, pp. 3-36; see also Rep. 68/1, Dept. Civ. Eng., Univ. of Toronto, 1968.

[9] Bażant Z. P., Asghari A., Schmidt J. - Experimental study of creep of hardened Portland cement paste at variable water content. Materials and Structures, RILEM, Paris, Vol. 9, 1976, pp. 279-290.

[10] Baz̈ant Z. P., Chern J. C. - Strain-softening with creep and exponential algorithm, Report No. 84-4/679 s, Center for Concrete and Geomaterials, Northwestern University; J. Engrg. Mech., ASCE, Vol. 111, 1985, No. 3.

[11] Bažant Z. P., Chern J. C. - Log-double power law for concrete creep, ACI Journal, in press; Triple power law for concrete creep. J. Engrg. Mech., ASCE, Vol. 111, No. 3, March 1985; Double power logarithmic creep law of concrete. Cem. Concr. Res., Vol. 14, No. 6, Dec. 1984.

[12] Bažant Z. P., NAJJar L. J. - Nonlinear water diffusion in nonsaturated concrete. Materials and Structures, RILEM, Vol. 5, 1972, pp. 3-20.

[13] BAŽANT Z. P., Он B. Н. - Crack band theory for fracture of concrete. Materials and Structures, Vol. 16, No. 93, 1983, pp. 155-177.

[14] BaŽAnt Z. P., Osman E. - Double-power law for basic creep of concrete. Materials and Structures, RILEM, Paris, Vol. 9, No. 49, 1976, pp. 3-11.

[15] Bažant Z. P., PAnula L. - Creep and shrinkage characterization for analyzing prestressed concrete structures. J. PCI, May-June, Vol. 25, 1980, pp. 86-122.

[16] Bažant Z. P., Panula L. - Practical prediction of timedependent deformation of concrete. Materials and Structures, Parts I and II: 11, No. 65, 1978, 307, Parts III and IV: 11 , No. 66 , p. $415,1978,415,1978$, Parts V and VI: Vol. 12, No. 69, 1979, p. 169

[17] BAZ̆ANT Z. P., RAFTShOL W. J. - Effect of cracking in drying and shrinkage specimens. Cem. Concr. Res., Vol. 12, 1982, pp. 209-226.

[18] BAŽANT Z. P., WANG T. S. - Spectral finite element analysis of random shrinkage in concrete structures. $\mathrm{J}$. Engrg. Mechanics, ASCE, Vol. 110, 1984, pp. 173-196.

[19] BažANT Z. P., Wu S. T. - Creep and shrinkage law for concrete at variable humidity. J. Engrg. Mech., ASCE, Vol. 100, 1974, pp. 1183-1209.

[20] BAŽANT Z. P., Wu S. T. - Rate-type creep law of aging concrete based on Maxwell chain. Materials and Structures, RILEM, Vol. 7, 1974, pp. 45-60.
[21] BAZ̆ANT Z. P., Wu S. T. - Thermoviscoelasticity of aging concrete, J. Engrg. Mech., ASCE, Vol. 100, June, 1974, pp. 575-597.

[22] Becker J., Bresler B. - Reinforced concrete frames in fire environments. Journal of the Structural Division, ASCE, Vol. 103, 1977, pp. 211-224.

[23] Brooks J. J., Neville A. M. - A comparison of creep, elasticity and strength of concrete in tension and in compression. Mag. Concr. Res., Vol. 29, No. 100, 1977, pp. 131-141.

[24] Brown N. H., Hope B. B. - The creep of hydrated cement paste. Cem. Concr. Res., Vol. 6, 1976, pp. 475486.

[25] Carlson R. W. - Drying shrinkage of large concrete members. J. Amer. Concr. Inst., Vol. 33, 1937, pp. 327 36.

[26] Cilosani Z. N. - On the true mechanism of creep of concrete (in Russian), Beton i Zhelezobeton (Moscow), Vol. 10, 1964, pp. 75-78.

[27] Davis R. E., Davis H. E., Brown E. H. - Plastic flow and volume change of concrete, ASTM Proc., Vol. 37, Part 2, 1937, pp. 317-330.

[28] Domone P. L. - Uniaxial tensile creep and failure of concrete. Mag. Concr. Res., Vol. 26, No. 88, September 1974, pp. 144-152.

[29] Feldman R. F., Sereda P. J. - A model for hydrated Portland cement paste as deduced from sorption-length change and mechanical properties. Materials and Structures, RILEM, Vol. 1, 1968, pp. 509-520.

[30] Gamble B. R., Parrot L. J. - Creep of concrete in compression during drying and wetting. Mag. Concr. Res., Vol. 30, No. 104, 1978, pp. 129-138.

[31] Glucklich J. - Rheological behavior of hardened cement paste under low stresses. J. Amer. Concr. Inst., Vol. 31, No. 4, 1959, pp. 327-337.

[32] Glucklich J., Ishai O. - Creep mechanism in cement mortar. J. Amer. Concr. Inst., Vol. 59, 1962, pp. 923948.

[33] Hanson J. A. - A ten-year study of creep properties of concrete. Concr. Lab., Report No. Sp-38, U.S. Dept. of the Interior, Bureau of Reclamation, Denver, Colorado, July 1953.

[34] Hope B. B., Brown N. H. - A model for the creep of concrete, Cem. Concr. Res., Vol. 5, 1975, pp. 577-586.

[35] HrenNikof A. - Shrinkage, swelling and creep in cement. J. Engrg. Mech. Div., Proc. ASCE, Vol. 85, EM3, 1959, p. 11 .

[36] Iding R., Bresler B. - Prediction of shrinkage stresses and deformations in concrete, in Fundamental Research on Creep and Shrinkage of Concrete, Wittmann F. H., Ed., Martinus Nijhoff, 1982.

[37] Illston J. M. - The creep of concrete under uniaxial tension. Mag. Concr. Res., Vol. 17, No. 51, June 1965, pp. $77-85$.

[38] Ishai O. - Elastic and inelastic behavior of cement mortar in torsion. Amer. Concr. Inst. Spec. Publ., SP-9, Symp. of Creep, Detroit, pp. 65-94. 1964, pp. 115-128; also see Ishai O., Glucklich J., The effect of extreme hygrometric changes on the isotropy and deformability of mortar and concrete specimens. RILEM Symp. on Moisture Problem in Building, Otaniemi, Finland, 1965, pp. 1-26.

[39] Jonasson J. E. - Analysis of creep and shrinkage in concrete and its application to concrete top layers. Cem. Concr. Res., Vol. 8, 1978, pp. 397-518.

[40] Klug P., Wittmann F. H. - Activation energy of creep of hardened cement paste. Materials and Structures, RILEM, Vol. 2, 1969, pp. 11-16.

[41] L'Hermite R. G., Mamillan M., Lefèvre C. - Nouveaux résultats de recherches sur la déformation et la 
rupture du béton. Annales de l'Institut Techn. du Bâtiment et des Travaux Publics, Vol. 18, No. 207-208, 1965, p. 325; see also Int. Conf. on the Structure of Concrete, Cement and Concrete Association, London, 1968, pp. 423.

[42] LyNAM G. G. - Growth and movement in Portland cement concrete. London, Oxford University Press, 1934, p. 139.

[43] Mamillan M. - Évolution du fluage et des propriétés du béton. Annales, Inst. Techn. du Bâtiment et des Travaux Publics, Vol. 21, 1969, p. 1033, and Vol. 13, 1960, pp. 1017-1052.

[44] Mamillan M., Lelan M. - Le fluage du béton. Annales Inst. Techn. du Bâtiment et des Travaux Publics (Supplément), Vol. 23, 1970, pp. 7-13, and Vol. 21, 1968, pp. 847-850.

[45] McDonald J. E. - Time dependent deformation of concrete under multiaxial stress conditions. U.S. Army Engineering Waterways Experiment Station, Vicksburg, Mississippi, Technical Report C-75-4 (to Oak Ridge National Laboratory, Oak Ridge, Tennessee), October 1975.

[46] Mullen W. G., Dolch W. L. - Creep of Portland cement paste. Proc. ASTM, Vol. 64, 1964, pp. 11461170.

[47] Pickett G. - The effect of change in moisture content on the creep of concrete under a sustained load. J. Am. Conc. Inst., Vol. 38, 1942, pp. 333-355; see also Shrinkage stresses in concrete. J. Amer. Concr. Inst., Vol. 47, 1946, pp. 165-204, 361-397.

[48] Powers T. C. - Mechanism of shrinkage and reversible creep of hardened cement paste. Int. Conf. on the Structure of Concrete, held in London in 1965, Cement and Concrete Assoc., London, 1968, pp. 319-344.

[49] Powers T. C. - Some observations on the interpretation of creep data. RILEM, Bulletin No. 33, December 1966, pp. 381-391.

[50] Powers T. C. - A discussion of cement hydration in relation to the curing of concrete. Proc. of the Highway Research Board, Vol. 27, 1947, pp. 178-188 (PCA Bulletin No. 25).
[51] Rosenberg D. U. - Methods for the numerical solution of partial differential equations. American Elsevier Publishing Co., Inc., New York, 1969.

[52] Ross A. D., Illston J. M., England G. L. - Short and long-term deformations of concrete as influenced by its physical structure and state. Int. Conf. on the Structure of Concrete, held in London, 1965, Cement and Concrete Association, 1968, pp. 407-422.

[53] RUETz W. - A hypothesis for the creep of hardened cement paste and the influence of simultaneous shrinkage. Int. Conf. on the Structure of Concrete, held in London, 1965, Cement and Concrete Association, 1968, pp. 365387; see also Deutscher Ausschuss für Stahlbeton, Heft 183, 1966.

[54] Straub F., Wittmann F. H. - Activation energy and activation volume of compressive and tensile creep of hardened cement paste. Proc., Conf. on Hydraulic Cement Pastes: Their Structure and Properties, Sheffield, 1976, pp. 227-230.

[55] Troxell G. E., Raphael J. M., Davis R. W. - Longtime creep and shrinkage tests of plain and reinforced concrete. Proc. ASTM, Vol. 58, 1958, pp. 1101-1120.

[56] WARD M. A., Cook D. J. - The mechanism of tensile creep in concrete, Mag. of Concr. Res., Vol. 21, No. 68, September 1969, pp. 151-158.

[57] Wittmann F. H. - Creep and shrinkage mechanisms, Chapter 6 in Bažant Z. P., Wittmann F. H., Eds, Creep and shrinkage in concrete structures, John Wiley and Sons, London, 1982, pp. 129-161.

[58] Wittmann F. H. - Einfluss des Feuchtigkeitsgehaltes auf das Kriechen des Zementsteins. Rheol. Acta., Vol. 9, 1970 , pp. 282-287.

[59] Wittmann F. H. - Surface tension, shrinkage and strength of hardened cement paste. Materials and Structures, RILEM, Vol. 1, 1968, pp. 547-552.

[60] Wittmann F. H., Roelfstra P. E. - Total deformation of loaded drying concrete. Cem. Concr. Res., Vol. 10, 1980, pp. 601-610.

[61] Zienkiewicz O. C. - The finite element method. McGraw-Hill Book Company, 1977, 785 p.

\section{RÉSUME}

Fluage du béton à humidité variable : loi constitutive et mécanisme. - La loi de fluage de type différentiel d'après une chaîne de Maxwell et relative au béton en cours de vieillissement, qui avait été formulée précédemment, est généralisée à une humidité variable et vérifiée par de nombreuses comparaisons avec les données d'essai disponibles dans la littérature. On porte une attention particulière à l'effet de Pickett, c'est-à-dire l'augmentation apparente du fluage due à un séchage simultané avec le chargement. Il apparaît que cet effet a quatre origines qui sont les suivantes par ordre décroissant d'importance: (a) retrait causé par la contrainte; (b) adoucissement en traction due à une fissuration progressive; (c) irréversibilité de la contraction au déchargement après la diminution de la contrainte en traction, et $(d)$ augmentation de la rigidité du matériau due au vieillissement (hydratation). Le modèle, qui est un cas particulier de la théorie thermodynamique précédemment avancée, repose sur une seule hypothèse concernant le mécanisme physique microscopique du fluage; le taux de fluage dépend de la grandeur du flux de microdiffusion de l'eau entre les macropores (pores capillaires) et les micropores $d u$ gel de ciment. En supposant que cette microdiffusion soit infiniment rapide, l'effet se réduit à ce que les viscosités du fluage dépendent d'un facteur temps de l'humidité interstitielle relative; on montre ensuite que ceci équivaut à un retrait provoqué par la contrainte, dans lequel le coefficient de fluage définissant le rapport des accroissements de fluage, déformation et humidité interstitielle relative dépend de la contrainte. En trois dimensions le coefficient de retrait devient ainsi un tenseur. Pour des raisons thermodynamiques, il doit exister aussi une dilatation thermique causée par la contrainte. Bien que la fissuration en traction contribue notablement à l'effet de Pickett, elle est bien insuffisante à l'expliquer entière ment. La théorie est en accord avec les données d'essai $d u$ fluage de base, du fluage d'éprouvettes avec une teneur 
en eau limitée à l'équilibre hygrométrique (préséché), $d u$ retrait, du gonflement et du fluage au séchage en compression, traction ou flexion. Le modèle d'amollissement de la déformation utilisé pour la fissuration en traction est le même que celui utilisé précédemment pour ajuster les données d'essai à partir des essais de rupture, de traction directe et de fléchissement de poutres renforcées. 